\title{
Solvating Alkylamine Hofmann Elimination in Zeolites Through Cooperative Adsorption
}

\author{
Han Chen ${ }^{\dagger}$ and Omar A. Abdelrahman ${ }^{t, \ddagger^{*}}$ \\ ${ }^{\dagger}$ Department of Chemical Engineering, University of Massachusetts Amherst, 686 N. Pleasant Street, Amherst, MA \\ 01003, USA \\ * Catalysis Center for Energy Innovation, University of Delaware, 150 Academy Street, Newark, DE 19716, USA \\ *Corresponding Author: abdel@umass.edu
}

Abstract. A kinetic investigation of the vapor phase Hofmann elimination of tert-butylamine over HZSM-5 reveals a carbocation mediated E1-like mechanism, where isobutene and ammonia are exclusively produced over Brønsted acid sites. Hofmann elimination kinetics are found to be insensitive to $\mathrm{Al}$ content or siting, varying only with alkylamine carbocation stability ( $r_{\text {tertiary }}>r_{\text {secondary }}>r_{\text {primary }}$ ). Under conditions of complete tert-butylamine surface coverage, experimentally measurable apparent kinetics are directly equivalent to the intrinsic kinetics of the rate determining unimolecular surface elimination. The direct measurement of elementary step kinetics served as a water-free reactive probe, providing a direct measurement of the impact of water on solid Brønsted acid catalyzed chemistries at a microscopic level. Over a range of temperatures $(453-513 \mathrm{~K})$ and tert-butylamine partial pressures $\left(6.8 \times 10^{-2}-6.8 \mathrm{kPa}\right)$, water reversibly inhibits the rate of Hofmann elimination. Despite expected changes in aluminosilicate hydrophobicity, the water-induced inhibition is found to be insensitive to $\mathrm{Al}$ content, demonstrated to be due to one water molecule per Brønsted acid site. Regardless of the significant reduction in the rate of Hofmann elimination, kinetic interrogations and operando spectroscopic measurements reveal that the coverage of TBA adsorbed on H-ZSM-5 is unaltered in the presence of water. Cooperative adsorption between the tert-butylammonium surface reactant and water adsorbed on a neighboring framework oxygen is proposed to be responsible for the observed rate inhibition, the surface dynamics of which is quantitatively captured through kinetic modeling of experimental rate measurements.

\section{Introduction. Zeolites have} been extensively used across a wide variety of industrial applications, ranging from chemical synthesis, adsorbents and molecular sieves..$^{1-3}$ In the context of catalytic conversions, aluminosilicate zeolites such as ZSM-5 have been commonly used as solid acids catalysts for a wide range of chemistries. ${ }^{4-5}$ Among the various chemistries, biomass upgrading over zeolites has received significant attention as a sustainable and alternative route to chemical production. ${ }^{6-11}$ Biomass catalytic upgrading strategies typically involve dehydration, decarboxylation, and aldol condensation. ${ }^{12-17}$ However, relative to petrochemical conversion strategies, the inherently higher water content of biomass poses a challenge, where its presence in the pores of a zeolite can significantly alter catalytic chemistries and kinetics. ${ }^{8,18-21}$ The impact of water on a zeolitecatalyzed chemistry has led to numerous investigations into the origin of the effect of water on catalytic process that leads to a change in reaction rates and selectivities. ${ }^{7,22-25}$ Major effects of water on the catalytic reactions include adsorption on active sites, ${ }^{26}$ solvation of reactants and transition states. ${ }^{27}$ Understanding the catalytic consequence of solvent environments like the aqueous phase is therefore central to designing solid acids for biomass catalytic upgrading strategies.

Aluminosilicates like ZSM-5 are frequently employed in aqueous phase reactions due to its excellent hydrothermal stability compared with some other commonly used zeolites. ${ }^{28}$ Due to the higher concentration of water at the catalyst surface, there are more water-active site interactions in the aqueous 
phase, where the surface hydrophobicity starts to play an important role. ${ }^{29}$ The choice of heteroatom content and synthesis method (e.g. defect free fluoride synthesis) $)^{24,30}$ can therefore alter the ability of water to tune a catalytic cycle; more hydrophilic surfaces characteristic of high $\mathrm{Al}^{3+}$ content and silanol defects are expected to facilitate larger intraporous water concentrations. ${ }^{29,31}$ For example, Lewis acid catalyzed epoxidation of 1-octene over Tisubstituted zeolite BEA is sensitive to water clusters hydrogen-bonded to silanol groups that interact with adsorbed reactants on neighboring active sites, while in a hydrophobic pore free of silanol defects, these short-distance interactions are rare as water cannot adsorb in the proximity of active sites. ${ }^{24,32}$ Water has also been proposed to change the catalytic activity of Brønsted acidic zeolites; co-feeding water was found to enhance the steady-state rate of alcohol dehydration by tuning the acidity of aluminosilicate zeolites, reducing the extent of coke formation. ${ }^{33-35}$ Phillips and Datta proposed that water clusters adsorbed on the surface of H-ZSM-5 hydrate surface protons, decreasing their Brønsted acidity as well as coke formation. ${ }^{33}$ Temperature programmed desorption studies of pyridine in liquid environments have also suggested the solvation of Brønsted acidic protons in aluminosilicates, facilitating the desorption of pyridine from zeolite surfaces. ${ }^{36}$ Given their larger proton affinities, water dimers and larger clusters have been reported to abstract protons from zeolite frameworks, forming hydronium cations. ${ }^{37-39}$ Conversely, Sauer et. al noted the absence of protonation for molecularly adsorbed water on H-ZSM-5 using inelastic neutron scattering, arguing against the presence of a hydroxonium ion. ${ }^{40}$

Developing an intimate understanding of water's impact on catalytic cycles requires an in-situ approach, leveraging kinetic and thermodynamic investigations under reaction conditions. Studies in this area have focused on leveraging probe chemistries, ${ }^{41-44}$ which can serve as a measure of the impact of water on solid acid catalyzed cycle. In the context of solid acid catalyzed reactions and specifically aluminosilicate zeolites, alcohol dehydration is a prototypical probe chemistry, used to kinetically interrogate aluminosilicate zeolites, ${ }^{45-47}$ the nature of a catalytic cycle ${ }^{48-51}$ and the effect of water on it.7, 23, 35 Water inhibits the rate of alcohol dehydration over solid acids, which is frequently attributed to a loss in active sites to water competitively adsorbing. ${ }^{6}, 21,52$ Conversely, Zhi et al. attributed the inhibitory effect of water on 1propanol dehydration to a preferential destabilization of the kinetically relevant transition state, concluding that water is too weakly bound to competitively adsorb on the zeolite surface. ${ }^{7}$ Similarly, for methanol dehydration over H-CHA, Di Iorio et. al proposed the water-methanol complexes inhibit catalytic dehydration, acting as inactive adsorbates from which no reaction proceeds. ${ }^{53}$ Furthermore, Mei and Lercher reported that vapor and aqueous phase cyclohexanol dehydration over H-BEA zeolite proceeds through different mechanisms due to intraporous water clusters acting as mobile Brønsted acid sites. ${ }^{25}$

While significant advances have been made in understanding the effect of water on zeolites and the catalytic cycles they facilitate, much of the existing literature relies on the use of a liquid phase reaction environment, or a probe chemistry where water is already involved. While intuitive, the use of a bulk liquid phase reaction environment introduces a host of thermodynamic non-idealities, which obfuscate the correlation of experimentally measurable macroscopic observables to microscopic information relevant to a catalytic cycle. Controlling the activity of water and reactants in solution is non-trivial when using water as a solvent itself. Similarly, probe chemistries which involve water as a reactant or product also pose a challenge, where the effect of water cannot be readily isolated. 
Designing a study that avoids the abovementioned challenges would provide greater insight into the impact of water on a solid acid catalytic cycle.

Here, we present an investigation into the effect of water on solid acid catalysts, using the Hofmann elimination of tert-butylamine (TBA) over H-ZSM-5 as a water-free probe reaction. Alkylamine Hofmann elimination is an exclusively Brønsted acid catalyzed chemistry, taking place over the Brønsted acidic bridging hydroxyls of aluminosilicate zeolites (Scheme 1). The vapor phase chemistry does not involve water as a reactant and/or product, nor require its presence as a solvent, allowing for precise control of the activity of water in the catalytic system. Alkylamines like TBA form stoichiometric adsorption complexes on a Brønsted acid site, ${ }^{54}$ providing a well-defined and readily characterized adsorbate $e^{55-57}$ to assess the impact of water on. A single carboncontaining product is selectively formed (isobutene) over a wide range of conditions, allowing us to more readily isolate the impact of water on Brønsted acid catalytic kinetics. ${ }^{58}$ These advantageous properties are also what have led to the widespread use of alkylamine Hofmann elimination as a means to quantify Brønsted acid site densities in aluminosilicates. ${ }^{58-62}$ Through a steady-state kinetic investigation, we demonstrate the unimolecular and E1-like nature of Hofmann elimination, establishing a kinetic baseline from which to understand the effect of water. Water vapor significantly impacted the rate of Hofmann elimination over H-ZSM-5, leading to an $\mathrm{Al}$ content-insensitive reduction in catalytic activity $(\mathrm{Si} / \mathrm{Al}=11.5-140)$. The inhibitory effect of water was found to be reversible in nature; the rate of Hofmann elimination is completely restored once water is removed. Through a combination of kinetic interrogation and operando catalyst characterization, we demonstrate that water inhibits the rate of Hofmann elimination without displacing any adsorbed TBA. Per active Brønsted acid site, only one water molecule is found to be responsible for the observed reduction in catalytic activity. While the coverage on Brønsted acid sites is dominated by TBA, water is proposed to adsorb on a framework oxygen adjacent to an adsorbed tert-butylammonium reactant, where the two adsorbates can interact. This cooperative adsorption of water and TBA results in the observed reduction in the catalytic rate of Hofmann elimination. The validity of the proposed cooperative adsorption mechanism is gauged through quantitative kinetic modeling, where it is found to capture experimentally measured rates over several orders of magnitude.

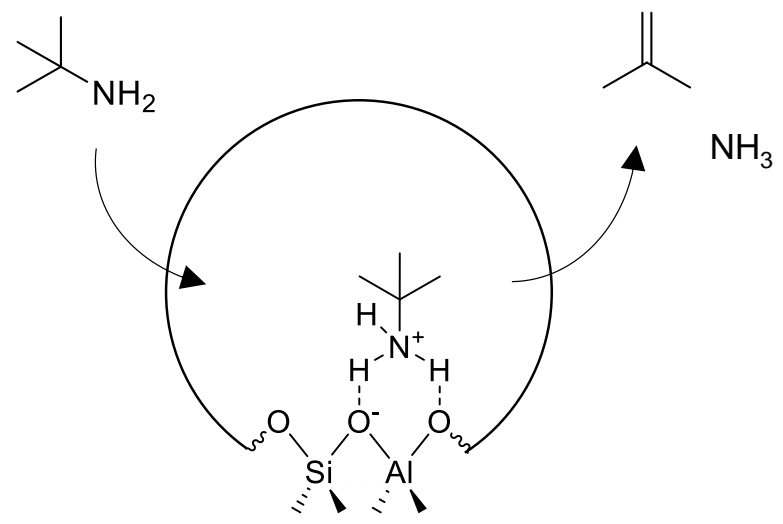

Scheme 1. Hofmann elimination of tert-butylamine (TBA) over an aluminosilicate Brønsted acid site.

\section{Experimental methods}

2.1. Materials. Tert-Butylamine (TBA, $\geq 99.5 \%$ ), sec-Butylamine (SBA, 99\%) and nButylamine (NBA, 99.5\%) were purchased from Sigma-Aldrich and dried with molecular sieves ( $3 \AA$ beads, 8-12 mesh, Sigma-Aldrich) overnight before use. Different concentrations of TBA/water mixture solutions were prepared using type 1 water $\left(>18.2 \mathrm{M} \Omega \mathrm{cm}^{-1}\right)$ for studying the effect of water on TBA Hofmann elimination. Ammonium form ZSM-5 (CBV2314, Si/Al = 11.5; CBV8014, Si/Al = 40; CBV28014, $\mathrm{Si} / \mathrm{Al}=140$ ) were obtained from Zeolyst. 
2.2. Catalyst pretreatment. To convert the zeolite from its ammonium $\left(\mathrm{NH}_{4}{ }^{+}\right)$to hydrogen $\left(\mathrm{H}^{+}\right)$form, all catalysts were subjected to an exsitu calcination. Typically, $0.5 \mathrm{~g}$ of catalyst sample was loaded into a downflow U-shape quartz tube and heated in a tube furnace (GSL$1100 \mathrm{X}$, MTI corporation) under a $100 \mathrm{sccm}$ flow of air (Ultra-zero, Airgas) regulated by a mass flow controller (5850S, Brooks Instrument). A plug of deactivated glass wool (24324, Restek) was placed at the bottom of the quartz U-tube as a physical support for the catalyst bed. All catalyst powders were calcined at $823 \mathrm{~K}$ for $10 \mathrm{hr}$ with a ramp rate of $2 \mathrm{~K} \min ^{-1}$. To ensure accurate calcination temperatures, a $1 / 16^{\prime \prime}$ type- $\mathrm{K}$ thermocouple (KQXL-116G-12, Omega) encased within a quartz sheath was placed in direct contact with the catalyst bed. Details of the ex-situ calcination system are provided in the supporting information (Sec. S1).

To ensure a reproducible particle size, calcined catalyst powders were pressed, crushed, and sieved to obtain a desired particle diameter. Briefly, 50-100 mg of calcined catalyst was loaded into a pellet press $(13 \mathrm{~mm}$ diameter, Pike Technologies) and pressed at 20 MPa of pressure using a hydraulic press (YLJ5-H, MTI corporation). The catalyst pellet was then broken into smaller particles and sieved (EW-59985-13 and EW-59985-18, Cole Parmer) to obtain the desired sieve fraction. The average catalyst particle diameter was controlled to be in the range of $106-250 \mu \mathrm{m}$; smaller particle diameters were avoided to minimize the pressure drop across the catalyst bed.

\subsection{Catalytic testing. Kinetic}

measurements were performed in a $1 / 2$ " quartz downflow packed bed reactor, with the catalyst bed resting on a plug of deactivated glass wool. The reactor was placed within a ceramic furnace, which controlled the temperature of the reactor only during pre-treatment (i.e. calcination) using a PID temperature controller (CN 7823, Omega). Catalysts were pre-treated via an in-situ calcination in $60 \mathrm{sccm}$ air at 823 $\mathrm{K}$ for $4 \mathrm{hr}$ with a ramp rate of $5 \mathrm{~K} \mathrm{~min}^{-1}$, then cooled to reaction temperature under the same flow rate of air. This entire heated reactor assembly was housed within a larger forced convection oven (5890 Series II, HP), which controlled the reactor temperature during kinetic measurements. This ensured the absence of temperature gradients across the reactor. The catalyst bed temperature was measured in-situ by placing a 1/16" thermocouple on top of the bed.

Liquid phase reactants were fed to a vaporization section through a 1/16" PEEK capillary line (0.01" I.D., TPK110, Vici Valco) using a syringe pump (Masterflex EW-7490504, Cole-Parmer) and air-tight glass syringes (Hamilton Company). The PEEK line was then connected to a $1 / 16$ " stainless-steel capillary line (0.01" I.D., T50C10D, Vici Valco) through a PEEK union (ZU1FPK, Vici Valco), and the other end of the stainless-steel capillary line was inserted inside the oven. The vaporized liquid was constantly swept by a stream of $\mathrm{He}$ (99.999\%, Airgas), the flow of which was adjusted by mass flow controllers (5850S, Brooks Instrument). In addition to the ex-situ drying of the TBA reactant, the vapor mixture (He+TBA) was dried in-situ by passing it through a bed of molecular sieve $3 \AA$ (regenerated daily at $493 \mathrm{~K}$ in $30 \mathrm{sccm}$ of $\mathrm{He}$ ). Prior to contacting TBA, He was purified by passing it through a moisture trap (22014, Restek), an oxygen trap (22010, Restek) and a liquid nitrogen cooled trap (in that order). The resulting dry vapor mixture was directed either to the reactor or a bypass line using a 6-port switching valve (A26UWE, Vici Valco). When directed to the bypass, a separate $100 \mathrm{sccm}$ stream of He stream purged the reactor. This allowed for the confirmation of the reactant partial pressure in the bypass, before exposing the catalyst to the reactant stream. Instantaneous switching between dry and wet 
reactant streams was achieved using two independent vaporizations sections, along with a 4-port switching valve (A24UWE, Vici Valco) controlling which stream was directed to the reactor. Both the 4 and 6-port switching valves were placed within a heated enclosure (HVE2, Vici Valco) to avoid any condensation. Additional details of the reactor system are provided in the supporting information (supporting information, Sec. S2). Reactor and bypass effluents were analyzed using an online gas chromatograph (7890B, Agilent) equipped with a HP-5 capillary column (19091J-413, Agilent) and a HP-PLOT Q Column (19091P-Q04, Agilent) connected to a flame ionization detector (FID) and coupled with a quantitative carbon detector (Polyarc, Activated research company). The transfer line between the reactor outlet and the gas chromatograph was resistively heated to $403 \mathrm{~K}$ to avoid any condensation using Nickel Chromium wire (8880K77, McMaster), insulated with a high-temperature wrap sleeving (6811A11, McMaster).

All kinetic measurements were performed between $453-513 \mathrm{~K}$ at 1.2 bar of total pressure; pressure drop across the catalyst bed was maintained below $10 \%$ of total pressure. Unless otherwise noted, the weight hourly space velocity (WHSV) was controlled anywhere between 0.2 and $212 \mathrm{~g} \mathrm{TBA} \mathrm{g} \mathrm{cat}^{-1} \mathrm{~h}^{-}$ ${ }^{1}$ while maintaining differential conditions with respect to TBA (<10\% conversion). Under all conditions tested, the attainable equilibrium conversion was greater than $99 \%$ (supporting information, Sec. S3). All carbon balances closed to within $\pm 10 \%$. Unless otherwise specified, all errors were calculated at a $95 \%$ confidence interval. The site time yield (STY) of Hofmann elimination was calculated as the molar flow rate of isobutene $\left(\mathrm{F}_{\mathrm{iC} 4}\right)$ normalized by the catalyst mass $\left(\mathrm{m}_{\mathrm{cat}}\right)$ and Brønsted acid site density ( $\left.\mathrm{S}_{\text {Brønsted }}\right)$,

$$
\mathrm{STY}=\frac{\mathrm{F}_{\mathrm{iC}_{4}}}{\mathrm{~m}_{\text {cat }} \mathrm{S}_{\text {Brønsted }}}[=] \frac{\text { mol of isobutene produced }}{\mathrm{mol}_{\text {of } \mathrm{H}^{+} \mathrm{s}}}
$$

\subsection{Catalyst Characterization. In-situ}

Fourier transform infrared (FT-IR) spectroscopy was performed to directly observe coverages under reaction conditions, using a Bruker Tensor II spectrometer equipped with a DLaTGS detector and mid-infrared source. Spectra were collected between 1000 and $6000 \mathrm{~cm}^{-1}$ with a $4 \mathrm{~cm}^{-1}$ resolution, averaged over 64 scans and subtracted from a background spectrum. Thin self-supporting catalyst wafers were prepared by pressing $10-$ $15 \mathrm{mg} \mathrm{cm}^{-2}$ of finely ground catalyst powder in a pellet press at $20 \mathrm{MPa}$ of pressure for 15 minutes. The catalyst wafer was then transferred to a custom-built heated transmission cell, equipped with water-cooled $\mathrm{CaF}_{2}$ windows. The temperature of the cell was controlled using a PID temperature controller (CN 7823, Omega) and a 1/16" type-K thermocouple, while a secondary thermocouple in a thermowell near the self-supporting wafer was used to report the catalyst temperature. The catalyst was first calcined in-situ (60 sccm ultra-zero air) at $673 \mathrm{~K}$ for $1 \mathrm{hr}$, using a ramp rate of $3 \mathrm{~K} \mathrm{~min}^{-1}$, after which it was cooled down to the desired temperature. Liquid phase probe molecules were fed to a vaporization section through a 1/16" PEEK capillary line (0.01" I.D., TPK110, Vici Valco) using a syringe pump (Masterflex EW-74905-04, ColeParmer) and air-tight glass syringes (Hamilton Company). The vaporized liquid was constantly swept by a stream of He $(99.999 \%$, Airgas), the flow of which was adjusted by mass flow controllers (Type 201, Porter). The vapor mixture was directed either to the heated transmission cell or a bypass line using a 6-port switching valve (A26UWE, Vici Valco) placed within a heated valve enclosure (HVEB, Vici Valco). Any tubing downstream of the vaporization section was additionally heat traced using resistively heated Nickel Chromium wire (8880K77, McMaster) to avoid condensation, insulated using a hightemperature wrap sleeving (6811A11, McMaster). 
Prior to exposing H-ZSM-5 to tert-butylamine, distinct silanol and Brønsted acidic bridging hydroxyl peaks were observed at 3741 and $3605 \mathrm{~cm}^{-1}$, ${ }^{63}$ respectively (Fig. 1A). Saturating the surface with tert-butylamine, the bridging hydroxyl peak completely disappeared, replaced by multiple lower wavenumber peaks associated with adsorbed tert-butylammonium (Fig. 1B). Two distinct N-H vibrational modes associated with adsorbed tert-butylammonium are observed at 1500 and $1609 \mathrm{~cm}^{-1}$, while three vibrational modes at 1475,1410 , and $1386 \mathrm{~cm}^{-1}$ are associated with various $\mathrm{C}-\mathrm{H}$ vibrational modes. $^{54,57}$

2.5. Temperature Programmed Methods. Temperature programmed surface reaction (TPSR) experiments were performed in the same packed bed reactor assembly discussed in sec 2.3, analyzing the effluent stream using high speed gas chromatography (1 sample per minute). The catalyst surface was first saturated with TBA at $423 \mathrm{~K}$ by exposing it to a $1.4 \mathrm{kPa}$ TBA containing stream of $\mathrm{He}(100 \mathrm{sccm})$ for 10 minutes, after which it was purged with a pure stream of He for 4 hours to remove any weakly adsorbed molecules. Once purged, the packed bed saturated with TBA was cooled to $373 \mathrm{~K}$.

A

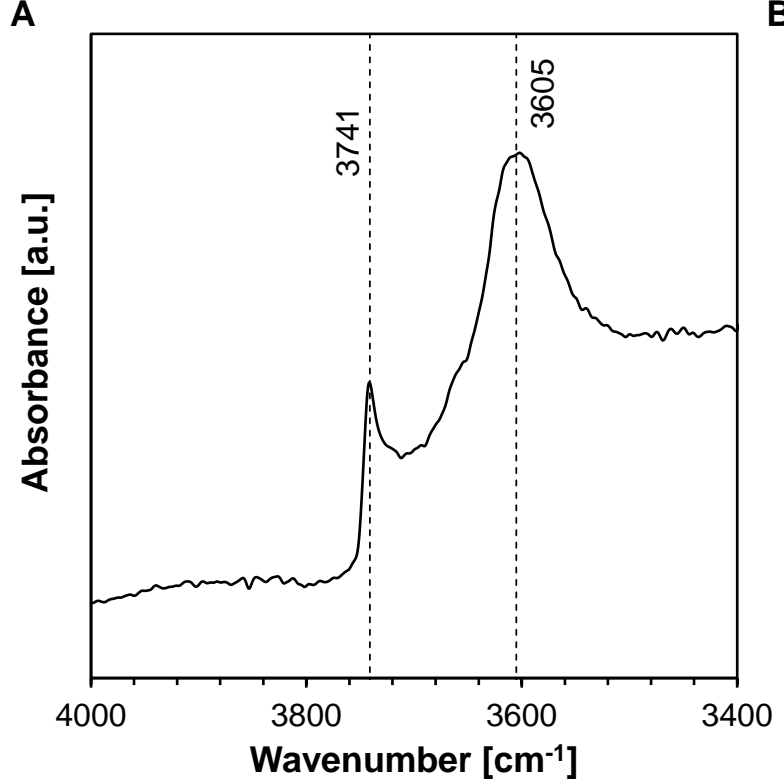

The catalyst bed temperature was the linearly ramped to $773 \mathrm{~K}$ at $10 \mathrm{~K} \mathrm{~min}^{-1}$ under a 200 sccm stream of He containing a controlled partial pressure of water.

\subsection{Kinetic Model Data Analysis.} Macroscopically measured site time yields over H-ZSM-5 in the presence and absence of water were rationalized through a kinetic model derived based on mechanistic and physical arguments. Sensitive parameters in the kinetic model were quantified through non-linear regression in MATLAB, estimating an optimal set of sensitive kinetic and thermodynamic parameters enabling the investigation of the enthalpic and entropic contributions in the presence of water. Defined as the sum of differences of experimentally measured $\left(\mathrm{STY}_{\exp }\right)$ and calculated site time yield $\left(\mathrm{STY}_{\text {cal }}\right)$, the sum of squared error (SSE, Eq. 2) was minimized by manipulating sensitive model parameters. The quality of the regression was also assessed using the coefficient of determination ( $\left.\mathrm{R}^{2}, \mathbf{E q} \cdot \mathbf{3}\right)$, calculated using SSE and the total sum of squares (SST, Eq. 4),

$$
\mathrm{SSE}=\sum_{\mathrm{i}=1}^{\mathrm{n}}\left(\mathrm{STY}_{\exp _{\mathrm{i}}}-\mathrm{STY}_{\mathrm{cal}_{\mathrm{i}}}\right)^{2}
$$

B

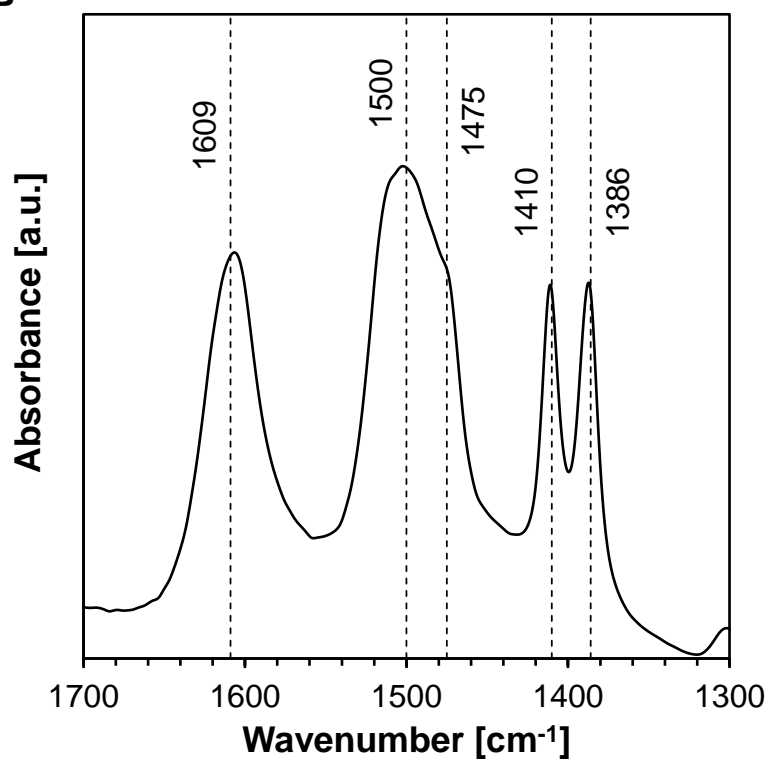

Figure 1. Infrared characterization of H-ZSM-5 Si/Al = 11.5 A. In-situ calcined zeolite surface in the absence of any probe molecules at $423 \mathrm{~K} \mathrm{~B}$. Saturated with tert-butylamine at $423 \mathrm{~K}$. 


$$
\begin{gathered}
\mathrm{R}^{2}=1-\frac{\mathrm{SSE}}{\mathrm{SST}} \\
\mathrm{SST}=\sum_{\mathrm{i}=1}^{\mathrm{n}}\left(\mathrm{STY}_{\exp _{\mathrm{i}}}-\overline{\mathrm{STY}_{\mathrm{cal}_{\mathrm{i}}}}\right)^{2}
\end{gathered}
$$

where $\overline{\mathrm{STY}_{\mathrm{cal}_{\mathrm{i}}}}$ is the average calculated site time yield through the kinetic model for a fixed set of operating conditions i. Details of the nonlinear regression script developed in MATLAB is available in the supporting information.

\section{Results \& discussion. Understanding} the effect of water on the overall catalytic cycle requires that the kinetics and mechanism of Hofmann elimination first be understood. We can then deviate from the base case Hofmann elimination catalytic cycle and perturb it using controlled partial pressure of water vapor. Over aluminosilicate zeolites, the Hofmann elimination of tert-butylamine (TBA) proceeds exclusively over Brønsted acid sites (BAS) with complete selectivity to isobutene and ammonia (Scheme 1) ${ }^{58}$ Despite the utility of this chemistry for characterizing solid acid catalysts, a detailed kinetic investigation that quantitatively describes macroscopically observed trends is lacking. Here, we first investigated the kinetics and mechanism of TBA Hofmann elimination over aluminosilicates.

\subsection{Establishing Reaction Kinetic}

Control. Given the kinetic diameter of the reactants and products relative to the MFI pore diameter $(\sim 5.5 \AA),{ }^{64}$ the rate of reaction relative to that of intraparticle diffusion can be limiting, obfuscating the measurement of reaction kinetics. The overall reaction is also significantly endothermic $\left(\Delta \mathrm{H}_{\mathrm{r}}{ }^{0}=56 \mathrm{~kJ} \mathrm{~mol}^{-1}\right)$, which may lead to non-trivial temperature distributions along the length of a catalyst particle. It is therefore necessary to examine the extent of any transport limitations. To this effect, we employed the Koros-Nowak criterion, verifying whether the rate changes linearly with active site density as expected by reaction kinetics control. ${ }^{65}$ The rate of TBA
Hofmann elimination was measured over three H-ZSM-5 catalysts with distinct $\mathrm{Si} / \mathrm{Al}$ ratios (11.5, 40 and 140), resulting in three distinct BAS densities which we have reported on previously. ${ }^{58}$ Additionally, rates were measured at two different temperatures to evaluate the extent of any significant heat transport limitations (473 and 493 K, Table 1). Through repeated initial rate measurements on multiple catalyst beds, we estimate our error in measuring the rate of Hofmann elimination to be $16 \%$ on average at a $95 \%$ confidence level (supporting information, Sec. S4). Within each temperature tested, the STY of Hofmann elimination varied by approximately a factor of two over the order of magnitude difference in active site density, indicating the absence of any significant heat or mass transport limitations. We therefore take the measured rates to be free of any transport limitations. The invariance of STY with $\mathrm{Si} / \mathrm{Al}$ ratio also indicates that $\mathrm{Al}$ pairs, which are more likely to form at lower $\mathrm{Si} / \mathrm{Al}$ ratios, ${ }^{66}$ do not play any significant role in the Hofmann elimination. Similarly, for the distance between neighboring BAS, the STY is unaffected by the number of Al atoms per unit cell. The STY of Hofmann elimination is identical whether over the BAS of a site isolated catalyst $(\mathrm{Si} / \mathrm{Al}=140)$, or those of an $\mathrm{Al}$ crowded pore $(\mathrm{Si} / \mathrm{Al}=11.5)$.

\subsection{Hofmann Elimination Kinetics. Over} the two order of magnitude range of tertbutylamine partial pressure investigated $\left(\mathrm{P}_{\mathrm{TBA}}\right.$ $=0.07-6.7 \mathrm{kPa}$ ), across the range of $\mathrm{Si} / \mathrm{Al}$ considered in this work, the Hofmann elimination exhibited a zeroth order dependence (Fig. 2A). The partial pressure independent behavior is observed at both 473 and $493 \mathrm{~K}$, suggesting a TBA covered surface. This can be rationalized based on reported heats of adsorption for TBA $\left(\Delta \mathrm{H}_{\mathrm{ads}}=-220 \mathrm{~kJ}\right.$ $\left.\mathrm{mol}^{-1}\right)^{67}$ relative to that of isobutene $\left(\Delta \mathrm{H}_{\mathrm{ads}}=-\right.$ $\left.74 \mathrm{~kJ} \mathrm{~mol}^{-1}\right)^{16}$ and ammonia $\left(\Delta \mathrm{H}_{\mathrm{ads}}=-145 \mathrm{~kJ}\right.$ $\left.\mathrm{mol}^{-1}\right)^{67}$ on a BAS; TBA strongly binds such that it dominates the surface coverage. This can 
Table 1. TBA Hofmann elimination over H-ZSM-5 with different $\mathrm{Si} / \mathrm{Al}$ ratios $(\mathrm{Si} / \mathrm{Al}=11.5,40,140)$ at $\mathrm{T}=473 \mathrm{~K}$ and $493 \mathrm{~K}$ with $\mathrm{P}_{\mathrm{TBA}}=1.4 \mathrm{kPa}$.

\begin{tabular}{|c|c|c|c|c|c|c|}
\hline $\mathbf{S i} / \mathbf{A l}^{\mathrm{a}}$ & $\begin{array}{c}\text { S }_{\text {Bronsted }}{ }^{\mathbf{b}} \\
{\left[\mu \mathrm{mol} \mathrm{g}^{-1}\right]}\end{array}$ & $\frac{\mathrm{Al}_{\mathrm{p}}^{\mathrm{c}}}{\mathrm{Al}_{\text {tot }}}$ & $\frac{\mathrm{Al}^{+\mathrm{d}}}{\text { u.c. }}$ & $\begin{array}{c}\text { Temperature } \\
{[\mathrm{K}]}\end{array}$ & $\begin{array}{c}\text { Rate } \\
{\left[\mu \mathrm{mol} \mathrm{iC}{ }_{4} \mathrm{~g}^{-1} \mathrm{~min}^{-1}\right]}\end{array}$ & $\begin{array}{c}\mathrm{STY} \times 10^{3} \\
{\left[\mathrm{~mol} \mathrm{iC}_{4}\left(\mathrm{~mol} \mathrm{H}^{+} \mathrm{s}\right)^{-1}\right]}\end{array}$ \\
\hline 11.5 & 1014 & 0.52 & 7.68 & 473 & 72.1 & 1.2 \\
\hline 40 & 335 & 0.30 & 2.34 & 473 & 47.0 & 2.3 \\
\hline 140 & 94 & 0.04 & 0.68 & 473 & 5.6 & 1.0 \\
\hline 11.5 & 1014 & 0.52 & 7.68 & 493 & 425.0 & 7.0 \\
\hline 40 & 335 & 0.30 & 2.34 & 493 & 239.0 & 11.9 \\
\hline 140 & 94 & 0.04 & 0.68 & 493 & 38.1 & 6.8 \\
\hline
\end{tabular}

a- As reported by vendor, b- ref. ${ }^{58}$, c- ref. ${ }^{68}$, d- 96/(1+Si/Al)

be further quantified by treating TBA as an immobile adsorbate (complete loss of translational and rotational gas phase entropy), where it is expected to have complete coverage under reaction conditions (supporting information, Sec. S5). A TBA covered surface under our reaction conditions is also consistent with isobutene amination studies where TBA induces product poisoning, blocking the access of isobutene and ammonia to the acid sites. ${ }^{57}$

Similar to the partial pressure dependence,

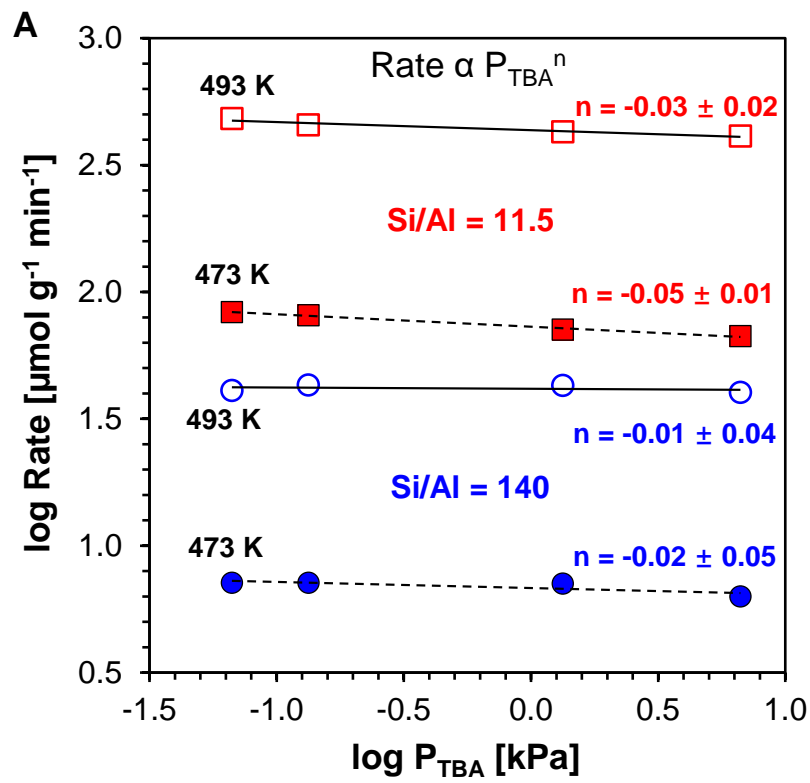

the apparent activation energy $\left(\mathrm{E}_{\mathrm{a}, \mathrm{app}}\right)$ is insensitive to $\mathrm{Al}$ content, with an average value of $173 \mathrm{~kJ} \mathrm{~mol}^{-1}$ (Fig. 2B). Malysheva et. al reported an activation energy of $142 \mathrm{~kJ} \mathrm{~mol}^{-1}$ for TBA Hofmann elimination over an amorphous aluminosilicate, albeit at higher temperatures $(>573 \mathrm{~K})$ where lower TBA coverages may exist and lead to a reduction in the apparent activation energy. ${ }^{69}$ They later reported an activation energy of $134 \mathrm{~kJ} \mathrm{~mol}^{-1}$ over a HNaY zeolite based on the

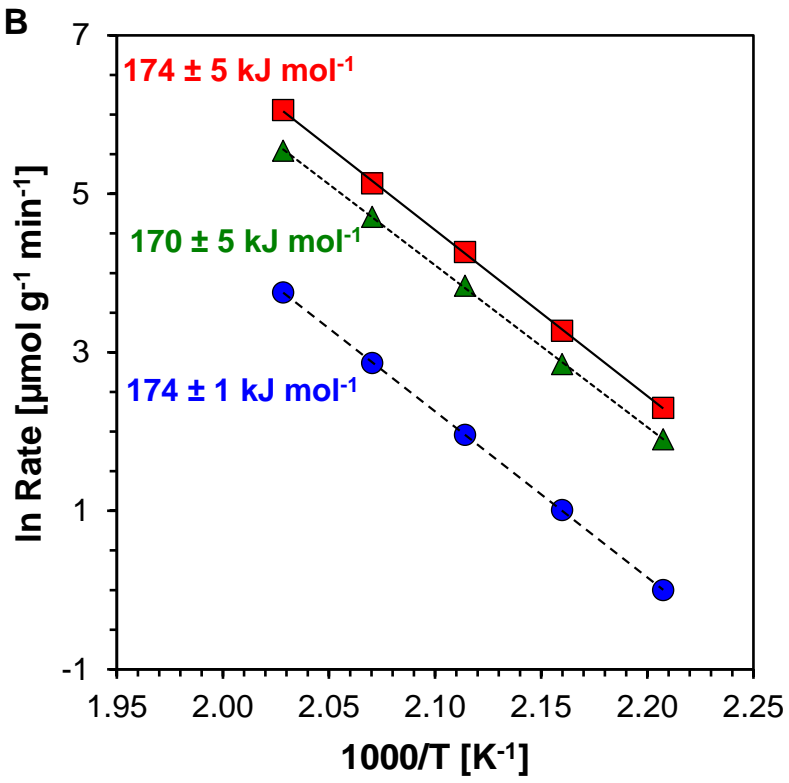

Figure 2. Kinetic measurements over $\mathrm{H}-\mathrm{ZSM}-5$ with varying $\mathrm{Si} / \mathrm{Al}$ ratios, $\mathrm{Si} / \mathrm{Al}=11.5(\square), 40(\Delta) 140$ (๑) A. TBA partial pressure dependence at $\mathrm{T}=473$ and $493 \mathrm{~K}$ with $\mathrm{P}_{\mathrm{TBA}}=0.07-6.7 \mathrm{kPa}$. Filled and unfilled symbols represent rates measured at 473 and $493 \mathrm{~K}$, respectively B. Activation energy measurement between $453-493 \mathrm{~K}$ with $\mathrm{P}_{\mathrm{TBA}}=1.4 \mathrm{kPa}$. 
disappearance of tert-butylammonium from the surface, as tracked by in-situ spectroscopy in a temperature programmed desorption. ${ }^{70}$ The lower activation energies reported by Malysheva et al. may be due to convoluting transport limitations. Extracting an activation energy from temperature programmed measurements performed under ambient pressures can be non-trivial, where readsorption and other diffusional effects are not readily eliminated. ${ }^{71-72}$ Gorte and coworkers have reported the TPD of TBA on HZSM-5 $(\mathrm{Si} / \mathrm{Al}=35)$ under vacuum conditions, where readsorption effects are negligible, observing a peak desorption temperature of 500 K. ${ }^{54}$ Converting this peak temperature to an activation energy based on a Redhead analysis(supporting information, Sec. S6), ${ }^{73}$ we calculate an activation energy of $174 \mathrm{~kJ} \mathrm{~mol}^{-1}$, in excellent agreement with the experimentally measured barrier under steady-state conditions.

\subsection{Hofmann Elimination Mechanism.} While certain details of the alkylamine Hofmann elimination mechanism over solid acids are debated, it is generally accepted that the cycle is initiated by the adsorption of TBA on a Brønsted acid site. ${ }^{70}$ Upon adsorption, the proton of the BAS is completely transferred to TBA, forming a stoichiometric tertbutylammonium ion pair complex with the framework oxygen (Scheme 2, path i) ${ }^{54,70}$ The presence of tert-butylammonium on the catalyst surface is consistent with infrared spectroscopy measurements that observe its formation upon TBA adsorption on H-ZSM-5 $\left(\sim 1500 \mathrm{~cm}^{-1}\right){ }^{54,} 57$ A surface elimination reaction involving tert-butylammonium, proceeding through an E1-like mechanism, ${ }^{74}$ leads to the formation of a tert-butyl carbocation (Scheme 2, path ii) and ammonia. The $\mathrm{C} 4$ carbocation then donates a $\beta$-hydrogen back to the aluminosilicate framework,

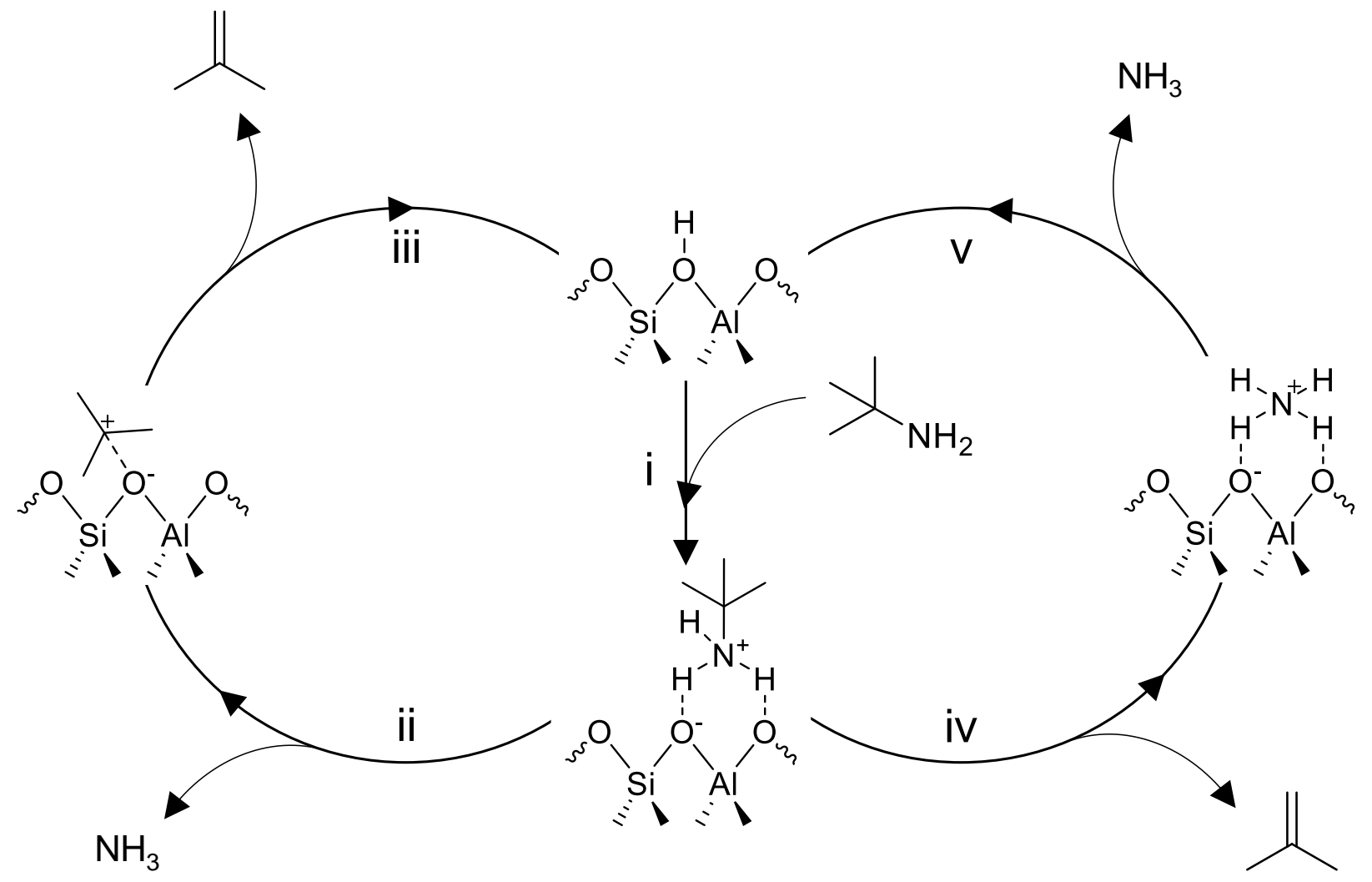

Scheme 2. Proposed mechanism for tert-butylamine Hofmann elimination over an aluminosilicate Brønsted acid site. 
desorbing as isobutene, and regenerating the BAS (Scheme 2, path iii). Alternatively, tertbutylammonium can decompose to an adsorbed ammonium ion while desorbing isobutene (Scheme 2, path iv), ${ }^{70}$ followed by the subsequent desorption of ammonia and regeneration of the BAS (Scheme 2, path v). ${ }^{70}$

While both pathways yield the same stable gas phase products, the energetic consequences are highly dependent on the prevailing pathway. For the carbocation mediated pathway, the stability of the surface carbocation will alter the activation energy of the surface Hofmann elimination. Conversely, for the ammonium mediated pathway, the same ammonium ion is formed regardless of the corresponding olefin product. The choice of alkylamine is therefore expected to affect the activation energetics of Hofmann elimination for the carbocation mediated pathway, but not for the ammonium ion mediated pathway. While a detailed kinetic study of multiple alkylamines is beyond the scope of this work, we can distinguish between the two pathways by comparing the activation energies of alklyamines with primary, secondary and tertiary $\alpha$-carbons. Over H-ZSM-5, the apparent activation energy follows the trend of n-butylamine $>$ sec-butylamine $>$ tertbutylamine (supporting information, Sec. S7). The trend in activation energies is consistent with temperature programmed desorption results where tert-butyl amine undergoes Hofmann elimination at a lower temperature than sec-butylamine over aluminosilicates, which in turn reacts at lower temperatures than n-butylamine. ${ }^{54-55,75} \mathrm{We}$ therefore conclude that the Hofmann elimination catalytic cycle proceeds through a carbocation mediated pathway, which can be represented through a combination of elementary steps presented in Table 2. While adsorbed ammonia is not explicitly involved in the proposed mechanism, the gaseous ammonia product can possibly adsorb on a BAS and we therefore account for this possibility (Step 4, Table 2).
Table 2. Elementary steps of TBA Hofmann elimination over a Brønsted acid site.

\section{Elementary Step}

\begin{tabular}{cc}
\hline 1 & $\mathrm{TBA}+* \rightleftharpoons \mathrm{TBA} *$ \\
2 & $\mathrm{TBA}^{*} \rightleftharpoons \mathrm{iC}_{4} *+\mathrm{NH}_{3}$ \\
3 & $\mathrm{iC}_{4}+* \rightleftharpoons \mathrm{iC}_{4}$ \\
4 & $\mathrm{NH}_{3}+* \rightleftharpoons \mathrm{NH}_{3}$ \\
\hline
\end{tabular}

Based on the proposed set of elementary steps, the zero-order behavior discussed in Sec. 3.2 is consistent with either the E1 surface elimination (Step 2) or product desorption (Step 3) acting as rate determining steps (supporting information, Sec. S8-S9). With a highly covered surface and unimolecular nature of either rate determining step, the apparent activation energy is equal to the elementary barrier $\left(\mathrm{E}_{\mathrm{a} \text {,app }}=\mathrm{E}_{\mathrm{a}}\right)$. Assuming non-activated isobutene adsorption $\left(\Delta \mathrm{H}_{\mathrm{ads}}=-\mathrm{E}_{\mathrm{a} \text {,des }}\right)$, the experimentally measured barrier $\left(173 \mathrm{~kJ} \mathrm{~mol}^{-1}\right)$ is inconsistent with the expected barrier for isobutene desorption. Bell et al. reported the first-principle calculated energetics for the reverse reaction, isobutene amination, over aluminosilicate zeolites. ${ }^{57}$ Given that microkinetic reversibility must be maintained, we estimate a barrier of $198 \mathrm{~kJ} \mathrm{~mol}^{-1}$ based on their reported calculations. We therefore take the overall rate of Hofmann elimination to be limited by the surface reaction (Step 2),

$$
\begin{gathered}
\mathrm{STY}=\mathrm{k} \cdot \theta_{\text {TBA }} \\
\mathrm{k}=\frac{\mathrm{ek}_{\mathrm{b}} \mathrm{T}}{\mathrm{h}} \exp \left(\frac{\Delta \mathrm{S}^{\ddagger}}{\mathrm{R}}\right) \exp \left(-\frac{\mathrm{E}_{\mathrm{a}}}{\mathrm{RT}}\right)
\end{gathered}
$$

where $\mathrm{k}$ and $\theta_{\mathrm{TBA}}$ are the forward kinetic rate constant for the surface Hofmann elimination and the fractional coverage of TBA, respectively. $\Delta \mathrm{S}^{\ddagger}$ is the entropy of activation for the surface Hofmann elimination, $\mathrm{k}_{\mathrm{b}}$ and $\mathrm{h}$ are 
the Boltzmann and Plank's constants, respectively. Given that the surface is saturated with TBA $\left(\theta_{\mathrm{TBA}}=1\right)$, we can take the overall rate of reaction to be equal to the intrinsic rate of the unimolecular surface reaction $(\mathrm{STY}=\mathrm{k})$. We can also examine the entropic aspect of the Hofmann elimination by considering the measured pre-exponential factor of $\sim 2 \times 10^{16} \mathrm{~s}^{-}$ 1 , corresponding to an activation entropy of 54 $\mathrm{J} \mathrm{mol}^{-1} \mathrm{~K}^{-1}$. Differing significantly from the standard pre-exponential factor of $10^{13} \mathrm{~s}^{-1}\left(\Delta \mathrm{S}^{\ddagger}\right.$ $=0$ ), the largely positive value indicates a highly mobile transition state that regains a significant degree of translational and/or rotational freedom. We previously reported a similar observation for the dehydradecyclization of tetrahydrofuran over H-ZSM5 , where transition states involving a complete proton transfer were found to exhibit entropies of activation of approximately $80 \mathrm{~J} \mathrm{~mol}^{-1} \mathrm{~K}^{-1}$ as a result of regaining two degrees of translational freedom. ${ }^{15}$

A

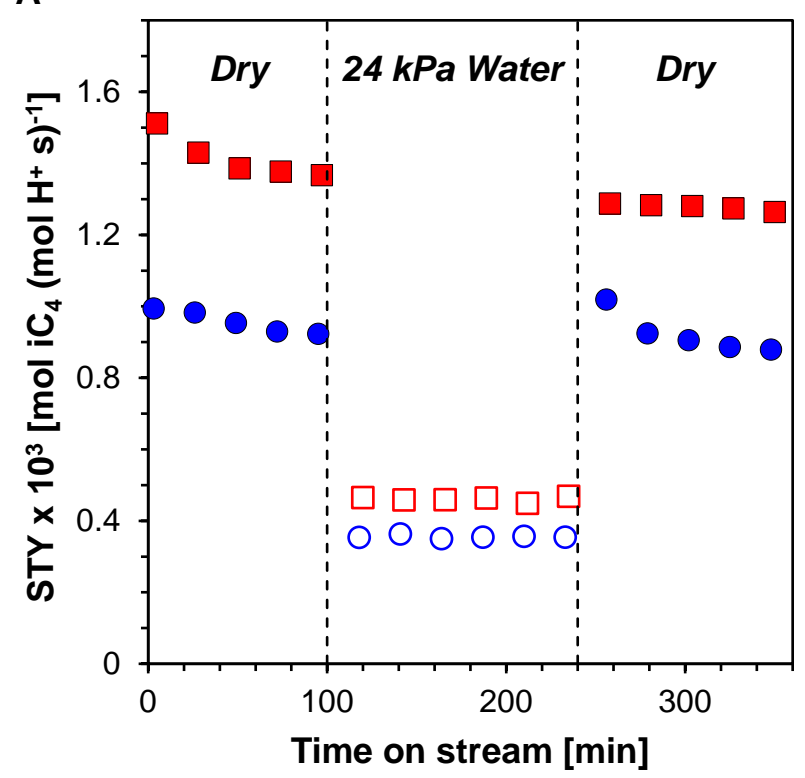

3.4. Effect of Water on Alkylamine Hofmann Elimination. Having established the kinetics of Hofmann elimination in the absence of water as a baseline, we then investigated the effect of water on the catalytic cycle through kinetic interrogation. We measured the rate of TBA Hofmann elimination in the presence of controlled partial pressures of water co-fed into the reactor; switching from a dry feed stream of $1.4 \mathrm{kPa}$ TBA at $473 \mathrm{~K}$ to an identical one with an additional $24 \mathrm{kPa}$ of water, the rate of Hofmann elimination instantaneously drops to less than half (Fig. 3A). The measured rate in the presence of water remains relatively stable with time on stream, suggesting that water did not induce any significant catalyst deactivation (e.g. steaming). ${ }^{76-77}$ This was confirmed by switching back to the initial dry feed stream, where catalytic activity was rapidly restored to the same level prior to water exposure. Given that isobutene can readily hydrolyze to tertbutanol over a Brønsted acid site in the presence of water, ${ }^{78-79}$ care was taken to

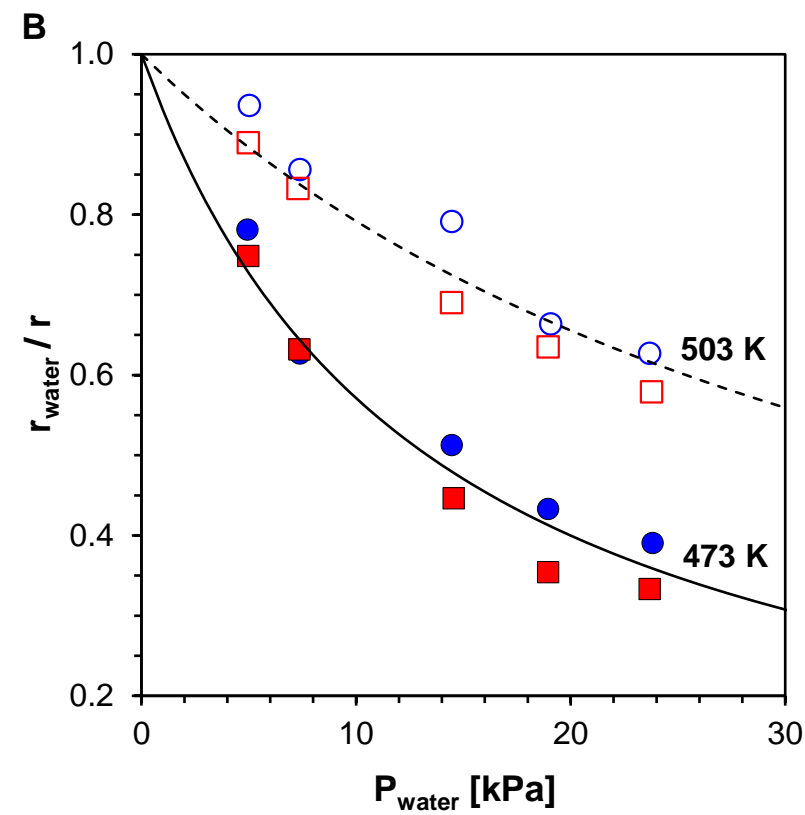

Figure 3. Effect of water co-feed over $\mathrm{H}-\mathrm{ZSM}-5$ with varying $\mathrm{Si} / \mathrm{Al}$ ratios, $\mathrm{Si} / \mathrm{Al}=\mathbf{1 1 . 5}(\square)$ and 140 (ө) at $T=473$ and $503 \mathrm{~K}$ with $P_{\text {TBA }}=1.4 \mathrm{kPa}$ A. Apparent STY of TBA Hofmann elimination under dry (filled) and water co-feed (unfilled, $24 \mathrm{kPa}$ water) conditions at $473 \mathrm{~K}$. B. Effect of water partial pressure co-fed $\left(\mathrm{P}_{\text {water }}\right)$ on ratio of rates $\left(\mathrm{r}_{\text {water }} / \mathrm{r}\right)$, filled and unfilled symbols represent ratios of rates at 473 and 503 $\mathrm{K}$, respectively. Solid and dashed lines are visual guides for observed trends at 473 and $503 \mathrm{~K}$, respectively. 
confirm the absence of any tert-butanol formation. As the partial pressure of water was increased further, the relative rate of Hofmann elimination $\left(r_{w a t e r} / r\right)$ continued to decrease (Fig. 3B). Holding $\mathrm{P}_{\mathrm{TBA}}$ fixed at $1.4 \mathrm{kPa}$ and varying the partial pressure of water from 5 to $24 \mathrm{kPa}$, a monotonic decrease in rate was observed. A similar trend held at higher temperatures $(503 \mathrm{~K})$, but with a less pronounced reduction in the rate of Hofmann elimination. Despite varying in hydrophobicity depending on $\mathrm{Al}$ content, ${ }^{29,} 31$ we observed relatively similar relative rates in the presence of water for H-ZSM-5 with $\mathrm{Si} / \mathrm{Al}$ ratios of 11.5 and 140. Here we emphasize the use of a relative rate given that it is unclear whether the activity per site is decreased, or a reduction in TBA coverage was experienced.

3.5. Water as a Competitive Adsorbate. The steady-state decrease and subsequent restoration of the rate of Hofmann elimination due to the introduction and removal of a water co-feed, respectively, is characteristic of a competitive adsorbate. A new surface coverage would rapidly be established upon introducing the water co-feed, but readily reversed once water vapor is removed from the feed stream. This constitutes a thermodynamic explanation for the observed effect of water; adsorbed water reduces the coverage of TBA $\left(\theta_{\mathrm{TBA}}<1\right)$ and thus the effective rate of Hofmann elimination. While the molecular heat of adsorption of water $\left(-46 \mathrm{~kJ} \mathrm{~mol}^{-1}\right)^{80-81}$ is trivial compared to that of TBA $\left(-220 \mathrm{~kJ} \mathrm{~mol}^{-1}\right),{ }^{67}$ water clusters that form at higher water partial pressures can potentially displace adsorbed TBA. Depending on the hydrophobicity of the catalyst surface, water clusters can have a more exothermic heat of adsorption relative to a single water molecule. ${ }^{80}$ Lee et al. proposed that water clusters have significantly larger proton affinities (837 and $937 \mathrm{~kJ} \mathrm{~mol}^{-1}$ for dimer and trimer, respectively) relative to a single water molecule $\left(724 \mathrm{~kJ} \mathrm{~mol}^{-}\right.$ $\left.{ }^{1}\right)$ and comparable to that of TBA. ${ }^{82-83}$ Given that the heat of adsorption on BAS is proportional to the proton affinity of the adsorbate, it is plausible that intraporous water clusters displace adsorbed TBA from a BAS. To quantitatively evaluate this possibility, we can explicitly define the adsorption of water on Brønsted acid sites,

$$
\mathrm{nW}+* \rightleftharpoons \mathrm{nW} *
$$

where ' $n$ ' is the number of adsorbed water molecules per Brønsted acid site $(n \geq 1)$. This treatment accounts for the possibility of water cluster formation, without making any assumptions apriori. By including the coverage of water in the site balance and treating its adsorption as quasi-equilibrated, we can expand the predicted STY expression for Hofmann elimination to account for adsorbed water (supporting information, Sec. S10),

$$
\frac{\mathrm{r}_{\mathrm{i}}}{\mathrm{S}_{\text {Brønsted }}}=\frac{\mathrm{kK}_{\mathrm{TBA}} \mathrm{P}_{\mathrm{TBA}}}{\left(\mathrm{K}_{\mathrm{TBA}} \mathrm{P}_{\mathrm{TBA}}+\mathrm{K}_{\mathrm{W}} \mathrm{P}_{\text {Water }}{ }^{n}\right)}
$$

where $\mathrm{K}_{\mathrm{TBA}}$ and $\mathrm{K}_{\mathrm{w}}$ are the adsorption equilibrium constants for TBA (Table 1, Step 1) and water (Eq. 7), respectively. In this context, any significant coverage of water adsorbed on a BAS will lead to a reduction in rate on account of the reduced TBA coverage. Linearizing the rate expression allow us to directly probe the average adsorption stoichiometry of water,

$$
\log \left(\frac{\mathrm{r}-\mathrm{r}_{\text {water }}}{\mathrm{r}_{\text {water }}}\right)=\log \left(\frac{\mathrm{K}_{\mathrm{W}}}{\mathrm{K}_{\mathrm{TBA}} \mathrm{P}_{\mathrm{TBA}}}\right)+n \log \mathrm{P}_{\text {Water }}
$$

where $r$ and $r_{\text {water }}$ are the rates of Hofmann elimination under dry and wet conditions, respectively. Across a range of water partial pressures $(5-24 \mathrm{kPa})$ and two different temperatures (473 and $503 \mathrm{~K}$ ), we find a slope of unity within experimental error $(n=1$, Fig. 4). This suggests that under the reaction conditions investigated, an adsorbed water cluster is unlikely to be responsible for the loss in catalytic activity. Per Brønsted acid site, a single water molecule is responsible for the observed reduction in the rate of Hofmann elimination. 


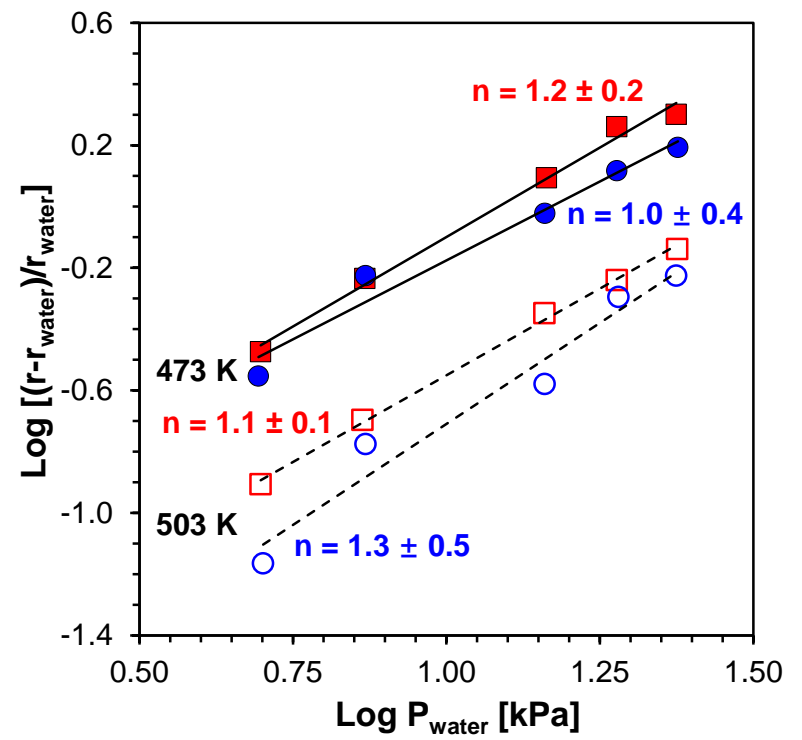

Figure 4. Linearization of competitive adsorption Langmuir-Hinshelwood reaction model (Eq. 9) over $\mathrm{Si} / \mathrm{Al}=11.5(\square)$ and $140(\bullet)$ at $\mathrm{T}=473$ and 503 $\mathrm{K}$ with $\mathrm{P}_{\mathrm{TBA}}=1.4 \mathrm{kPa}$.

While the prevalence of water clusters in zeolite frameworks is frequently reported, ${ }^{83-}$ 85 they are unstable at elevated temperatures due to the decrease in the number of intermolecular hydrogen bonds. ${ }^{86-87}$ Alternatively, it is possible that the relatively bulky TBA molecule occupies a significant fraction of the pore volume, making the formation of water clusters sterically unfavorable.

Despite the result demonstrating that per Brønsted acid site, only one water molecule is responsible for the loss in catalytic activity, it remains improbable that molecularly adsorbed water can competitively adsorb on a BAS in the presence of TBA. The sheer difference in the proton affinity of the adsorbates (PAwater $=691 \mathrm{~kJ}$ mol-1, PATBA $=934 \mathrm{~kJ}$ mol-1), reflected in their respective heats of adsorption, precludes the possibility of competitive adsorption. Nevertheless, if water were in fact able to act as a competitive adsorbate, one would expect the Langmuir based model (Eq. 8) to be valid across a range of conditions. Rearranging Eq. 8, the rate of Hofmann elimination is predicted to be solely a function of the ratio of water and TBA partial pressures $\left(\mathrm{P}_{\text {water }} / \mathrm{P}_{\mathrm{TBA}}\right)$,

$$
\frac{\mathrm{r}_{\mathrm{i}}}{\mathrm{S}_{\mathrm{Br} ø \text { sted }}}=\frac{\mathrm{k}}{1+\frac{\mathrm{K}_{\mathrm{W}}}{\mathrm{K}_{\mathrm{TBA}}} \frac{\mathrm{P}_{\mathrm{water}}}{\mathrm{P}_{\mathrm{TBA}}}}
$$
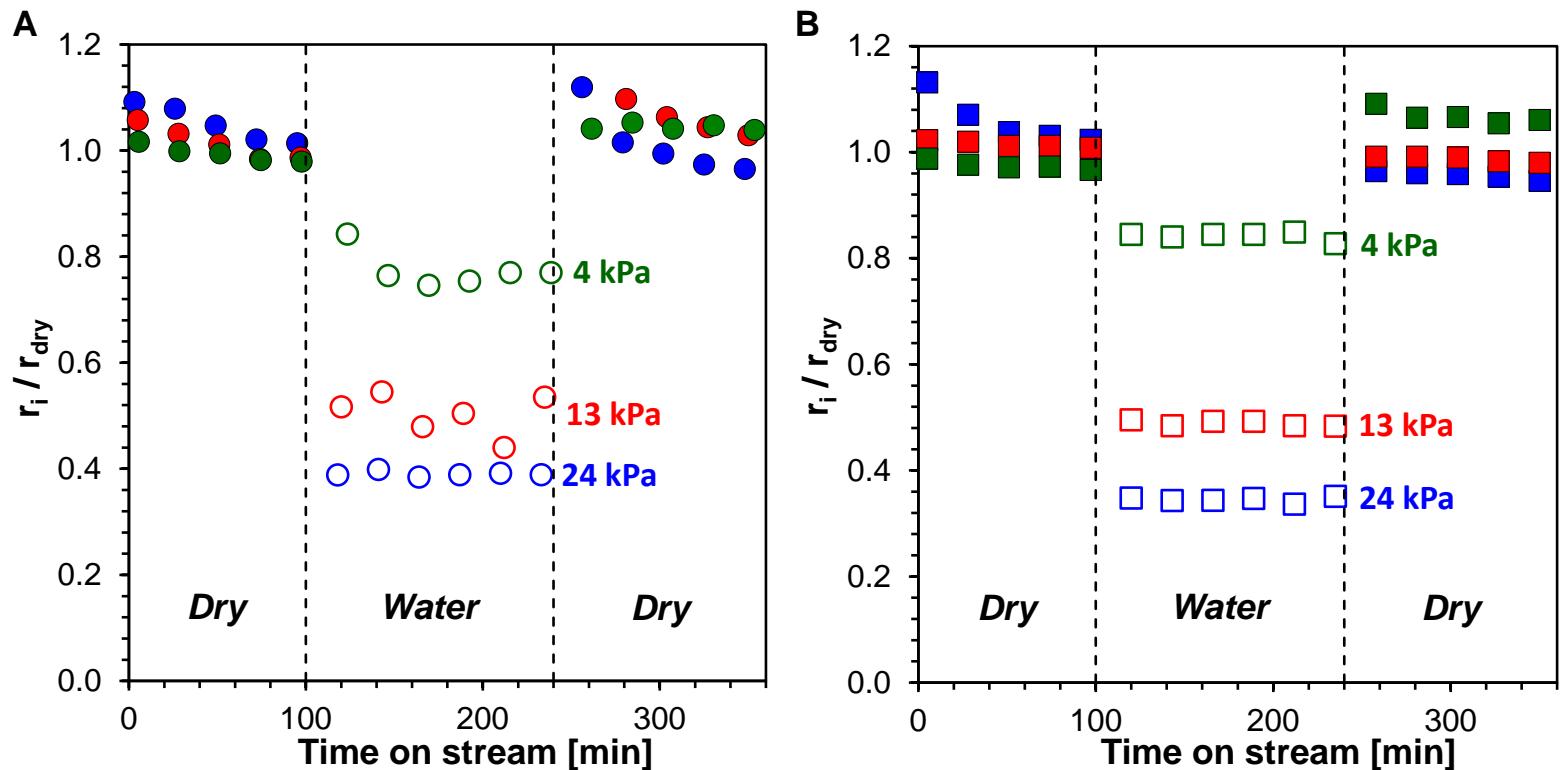

Figure 5. Effect of water with fixed $P_{\text {water }} / P_{\text {TBA }}$ ratio versus time on stream at $P_{\text {water }}=4$ (green), 13 (red) and 24 (blue) $\mathbf{k P a}$ at $\mathrm{T}=473 \mathrm{~K} \mathrm{~A} . \mathrm{Si} / \mathrm{Al}=140 \mathrm{~B} . \mathrm{Si} / \mathrm{Al}=11.5$. Filled and unfilled symbols represent dry and wet conditions, respectively. 
regardless of the absolute partial pressures of water and/or TBA. However, despite fixing the partial pressure ratio of water to TBA at a value of 19, the rate of Hofmann elimination decreases with increasing water partial pressure (Fig. 5). This suggests that the mechanism through which water alters the rate of Hofmann elimination is unlikely to be that of a simple competitive adsorption.

\subsection{Water as a Non-Competitive} Adsorbate. While water may not be able to competitively adsorb against TBA on a Brønsted acid site, it is necessary to consider whether water can affect the catalytic cycle through a non-competitive adsorption mechanism. Previous studies have suggested that the choice of solvent environment affects the desorption energy of pyridine from a Brønsted acid site, desorbing more readily in an aqueous environment than in vacuum. ${ }^{36}$ It is therefore possible that while water does not competitively adsorb, it reduces the binding energy and coverage of TBA, resulting in an apparent decrease in rate.

Keeping the partial pressure of water

A

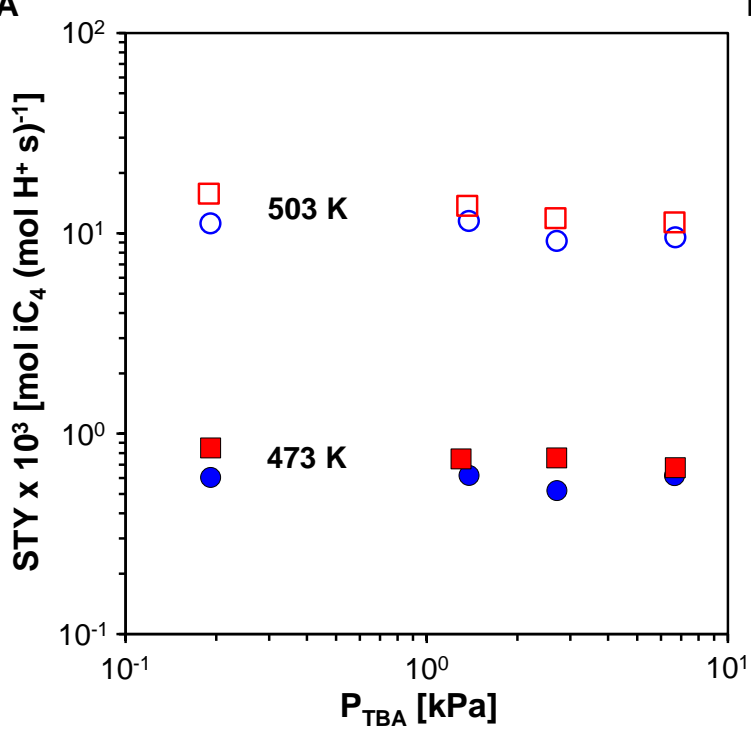

fixed at $7.3 \mathrm{kPa}$, we can examine the partial pressure dependency of TBA (Fig. 6A). Similar to the zeroth order behavior under dry conditions, the rate of Hofmann elimination in the presence of water is diminished but remains insensitive to the partial pressure of TBA. As discussed in Sec. 3.2, such zero-order behavior is interpreted as a TBA-saturated surface $\left(\theta_{\text {TBA }}\right.$ $\left.=\theta_{\mathrm{TBA}, \text { wet }}=1\right)$. Water is therefore found to reduce the rate of Hofmann elimination, without affecting the coverage of TBA on Brønsted acid sites. Identical trends have been reported in other chemistries where noncompetitive adsorption has been invoked to explain measured kinetic trends. Hydrogenation over group VIII metals often exhibits zero order partial pressure dependency in the unsaturated moiety, interpreted as a highly covered metal surface where hydrogen non-competitively adsorbs in three-fold hollows. ${ }^{88}$ We further confirmed the lack of competition between water and TBA through in-situ IR characterization of the catalyst surface, by tracking the integrated area of the adsorbed tert-butylammonium N-H deformation mode at $1500 \mathrm{~cm}^{-1}$ under reaction

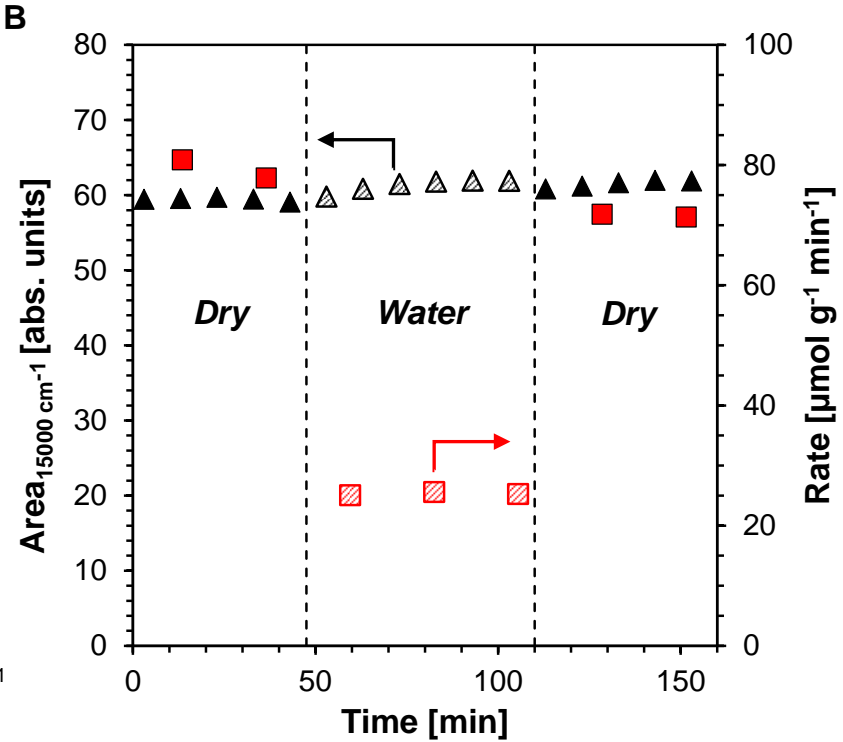

Figure 6. Alkylamine coverage changes with water A. Tert-butylamine partial pressure dependence in the presence of a water co-feed. $\mathrm{Si} / \mathrm{Al}=11.5(\square)$ and $\mathrm{Si} / \mathrm{Al}=140(\bullet)$ at $473 \mathrm{~K}$ (filled) and $503 \mathrm{~K}$ (unfilled). $\mathrm{P}_{\mathrm{TBA}}=0.2-6.7 \mathrm{kPa}$ and $\mathrm{P}_{\text {water }}=7.3 \mathrm{kPa}$ B. FT-IR integrated area of tert-butylammonium N-H deformation mode $\left(1500 \mathrm{~cm}^{-1}, \boldsymbol{\Delta}\right)$ and the corresponding rate of Hofmann elimination ( $\square$ ) with time on stream in the presence (filled) and absence (patterned) of $24 \mathrm{kPa}$ of water. $\mathrm{P}_{\mathrm{TBA}}=1.4 \mathrm{kPa}, \mathrm{T}=473 \mathrm{~K}, \mathrm{Si} / \mathrm{Al}=11.5$. 
conditions. ${ }^{54,57}$ In the presence of a $24 \mathrm{kPa}$ water co-feed, no significant change in the integrated peak area was observed relative to the absence of water (Fig. 6B). The rate of Hofmann elimination, however, decreased by $\sim 70 \%$ in contrast to the unchanged tertbutylammonium coverage. This provides direct evidence for the lack of competitive adsorption between water and tert-butylamine on a Brønsted acid site, despite molecular water inhibiting the rate of Hofmann elimination.

\subsection{Apparent and Intrinsic Activation} Energetics. As discussed in Sec. 3.3, the apparent activation energy over the TBA covered surface is equal to the intrinsic activation energy of the rate determining E1 elementary step in the absence of water. In the presence of water, an increase in the apparent activation energy of Hofmann elimination (174 vs $203 \mathrm{~kJ} \mathrm{~mol}^{-1}$, Fig. 7A) was observed. While TBA continued to dominate the fractional coverage on Brønsted acid sites, the coverage of water on the surface and/or its interaction with tert-butylammonium obfuscates the

A

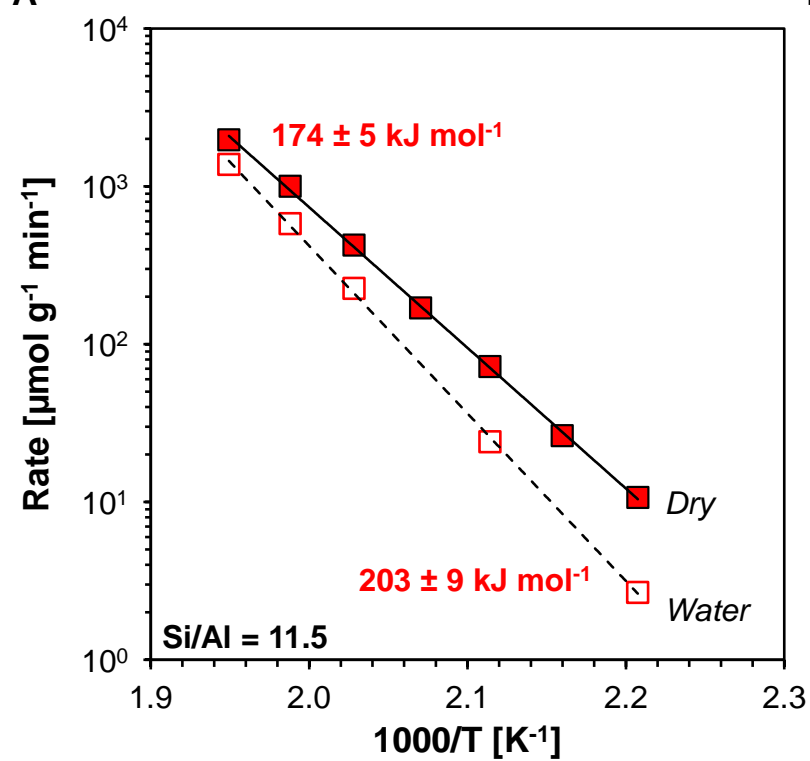

immediate interpretation of the apparent activation energy. We therefore turned to temperature programmed surface reaction (TPSR) methods, which allowed us to directly investigate the activation energetics of the rate determining step. Taking the measured activation energy and entropy under steadystate experimental conditions in the absence of water $\left(\Delta \mathrm{S}^{\ddagger}=54 \mathrm{~J} \mathrm{~mol}^{-1} \mathrm{~K}^{-1}, \mathrm{E}_{\mathrm{a}}=173 \mathrm{~kJ} \mathrm{~mol}^{-1}\right.$, Sec. 3.3), we calculated the predicted TPSR curve for TBA Hofmann elimination using a $1^{\text {st }}$ order Polanyi-Wigner equation (supporting information, TPSR.m), which was found to be in excellent agreement with previously reported experimentally measured TBA-TPSR curves. ${ }^{54}$ We then compared the predicted TPSR curve with one experimentally measured in a $24 \mathrm{kPa}$ water environment, where they were found to be in excellent agreement (Fig. 7B). It is worth noting here that no fitting was applied to the Polanyi-Wigner predicted TPSR curve based on the experimentally measured water environment TPSR. Had the observed increase in apparent activation energy $(\sim 30 \mathrm{~kJ}$ $\left.\mathrm{mol}^{-1}\right)$ been due to a true change in the intrinsic

B

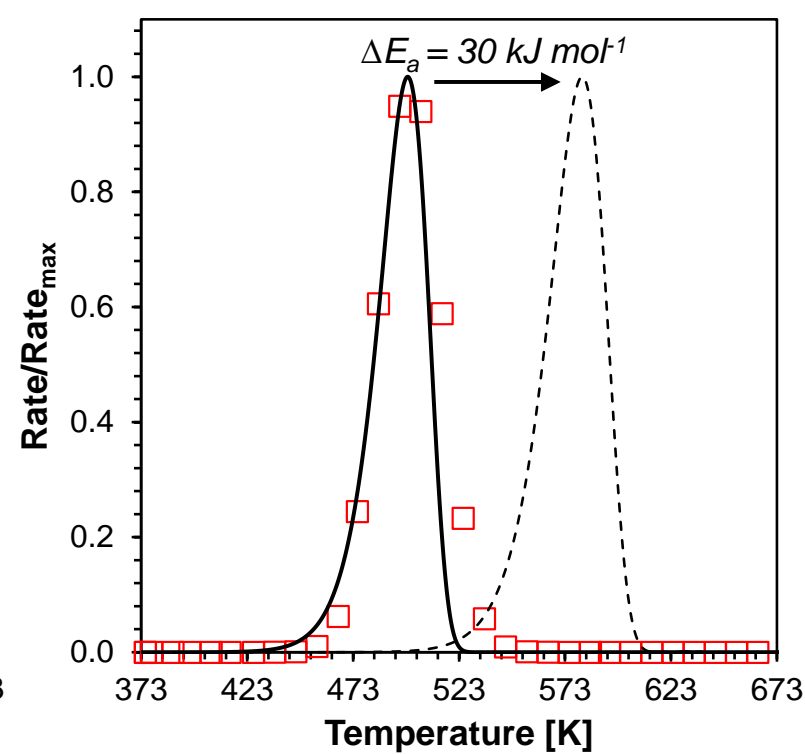

Figure 7. Activation Energetics in the presence $(\square)$ and absence $(\square)$ of $24 \mathrm{kPa}$ water over H-ZSM-5 $(\mathbf{S i} / \mathbf{A l}=\mathbf{1 1 . 5}) \mathbf{A}$. Measured apparent activation energy between $453-513 \mathrm{~K}, \mathrm{P}_{\mathrm{TBA}}=1.4 \mathrm{kPa} \mathbf{B}$. Temperature programmed surface reaction of pre-adsorbed TBA in water environment $(\square)$, compared against PolanyiWigner predicted water-free TPSR (-) and with a $30 \mathrm{~kJ} \mathrm{~mol}^{-1}$ increased activation energy (---) between 373 $-773 \mathrm{~K}$, with a $10 \mathrm{~K} \mathrm{~min}^{-1}$ ramp rate. 
kinetics of Hofmann elimination, the peak position of the TPSR curve was expected to shift to higher temperatures by $\sim 70 \mathrm{~K}$ (Fig. 7B, dashed). The shift in the position of the TPSR curve is assuming that the entropy of activation does not change as the activation energy increases, which was found to hold true when comparing the activation energetics of nbutylamine, sec-butylamine and tertbutylamine (supporting information, Fig. S4). The observed water-induced increase in the apparent activation energy cannot be attributed to a true increase in the intrinsic barrier to Hofmann elimination.

\subsection{Water and TBA Cooperative} Adsorption. Having ruled out any significant competition between water and TBA over a Brønsted acid site, combined with the lack of change in the intrinsic barrier, we propose a cooperative adsorption mechanism between TBA and Water (Scheme 3). Water adsorbs on a framework oxygen neighboring the tertbutylammonium adsorbate, where the proximity of the chemisorbed and physisorbed TBA allows them to interact, leading to a cooperative adsorption between the two molecules. The adsorbed Water-TBA complex is stabilized relative to the 'dry' tertbutylammonium complex, as water forms hydrogen bonds with the adsorbed tertbutylammonium, inhibiting the Hofmann elimination catalytic cycle. The formation of water-adsorbate complexes has been previously proposed for methanol ${ }^{53}$ and propanol $^{7}$ adsorbing on the Brønsted acid sites of aluminosilicates. However, contrary to prior reports, the Brønsted acidic proton is not shared with water, remaining completely transferred to tert-butylamine, as evidenced by the lack of change observed for the tert-butylammonium IR band in the presence of water (Fig. 6B). With increasing temperature, the cooperative adsorption of water becomes less favorable, leading to a smaller inhibitory effect of water at elevated temperatures. The intrinsic rate of
Hofmann elimination increases with temperature, while the coverage of the kinetically inhibited TBA-Water cooperative adsorbate decreases. Both changes lead to an increase in the apparent rate of Hofmann elimination. Therefore, while the intrinsic activation energy to Hofmann elimination on the surface is unchanged, the apparent barrier in the presence of water is increased.

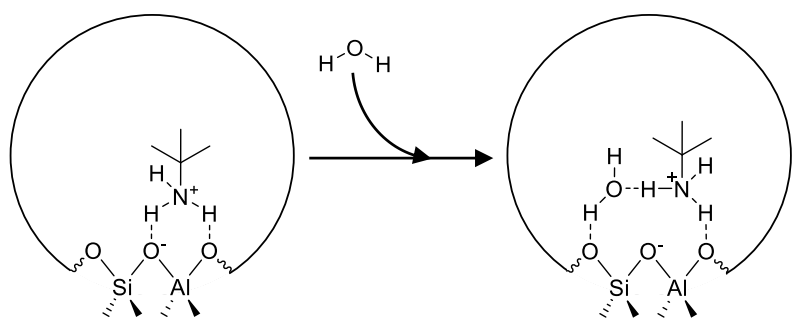

Scheme 3. Cooperative adsorption mechanism between tert-butylammonium and molecular water

3.9. Kinetic Modeling. While all the arguments discussed so far point to a cooperative adsorption of TBA and water, the discussion has focused on rationalizing overall kinetic trends based on expected reaction orders. However, to better assess the plausibility of the proposed mechanism through which water impacts the Hofmann elimination catalytic cycle, the cooperative adsorption mechanism was quantitatively examined through kinetic modeling.

3.9.1. Initial Parameter Estimation. As discussed in Section 3.3, the Hofmann elimination reaction proceeds via a ratedetermining E1 mechanism involving adsorbed tert-butylammonium (Table 2, Step 2). Adding the cooperative adsorption of water to the existing set of elementary steps, the rate of Hofmann elimination in the absence and presence of water is defined through a single rate expression,

$$
\begin{gathered}
\mathrm{W}+\mathrm{TBA} * \rightleftharpoons \mathrm{W}-\mathrm{TBA} * \\
\frac{\mathrm{r}}{\mathrm{S}_{\mathrm{Br} ø n s t e d}}=\frac{\overrightarrow{\mathrm{k}_{2} \mathrm{~K}_{\mathrm{TBA}} \mathrm{P}_{\mathrm{TBA}}}}{\left(1+\mathrm{K}_{\mathrm{TBA}} \mathrm{P}_{\mathrm{TBA}}+\mathrm{K}_{\mathrm{Water}} \mathrm{K}_{\mathrm{TBA}} \mathrm{P}_{\mathrm{TBA}} \mathrm{P}_{\text {Water }}\right)}
\end{gathered}
$$




\section{Chem Rxiv}

$$
\mathrm{K}_{\mathrm{i}}=\exp \left(\frac{\Delta \mathrm{S}_{\mathrm{ads}, \mathrm{i}}}{\mathrm{R}}\right) \cdot \exp \left(\frac{-\Delta \mathrm{H}_{\mathrm{ads}, \mathrm{i}}}{\mathrm{RT}}\right)
$$

six parameters are involved in the model, enthalpies and entropies of adsorption for TBA and water $\left(\Delta \mathrm{H}_{\text {ads,TBA }}, \Delta \mathrm{S}_{\text {ads,TBA }}, \Delta \mathrm{H}_{\text {ads,water, }}\right.$, and $\Delta \mathrm{S}_{\text {ads,water }}$ ) as well as enthalpy and entropy of activation $\left(\Delta \mathrm{H}^{\ddagger}\right.$ and $\left.\Delta \mathrm{S}^{\ddagger}\right)$. Given their relatively similar proton affinities, we estimate the heat of adsorption of TBA based on the reported experimentally measured value for nbutylamine on H-ZSM-5 $\left(-220 \mathrm{~kJ} \mathrm{~mol}^{-1}\right) .{ }^{67}$ The highly exothermic adsorption suggests a strongly bound molecule, allowing us to estimate its entropy of adsorption as a complete loss of translational and rotational motions $\left(270 \mathrm{~J} \mathrm{~mol}^{-1} \mathrm{~K}^{-1}\right)$. The observed kinetic trends are the result of a single adsorbed water molecule per Brønsted acid site, thus we accordingly estimate the heat of adsorption of water based on experimental adsorption calorimetry for a single molecularly adsorbed water on H-ZSM-5 (-46 kJ mol-1). ${ }^{80-81}$ The entropy of adsorption for water was estimated based on a correlation by Abdelrahman and Dauenhauer for molecular adsorption in zeolites $\left(-65 \mathrm{~J} \mathrm{~mol}^{-1} \mathrm{~K}^{-1}\right){ }^{89}$ Initial estimates of $\Delta \mathrm{H}^{\ddagger}\left(197 \mathrm{~kJ} \mathrm{~mol}^{-1}\right)$ and $\Delta \mathrm{S}^{\ddagger}\left(214 \mathrm{~J} \mathrm{~mol}^{-1} \mathrm{~K}^{-1}\right)$ were obtained from density functional theory calculations by Bell and co-workers. ${ }^{57}$ Applying these initial estimates and calculating the predicted STY of Hofmann elimination reveals that the model does not capture macroscopically observed trends, as indicated by a negative $\mathrm{R}^{2}$ and large sum of squared errors (Table 3), warranting a regression of the parameters to the experimentally measured STYs.

3.9.2. Sensitivity Analysis. To avoid overfitting the identified energetic parameters through regression, a sensitivity analysis based on the initial estimates was performed to determine if the model was sensitive to all six parameters (supporting information, Sensitivity.m). With a $1 \%$ perturbation (positive and negative) applied to each parameter, the model was found to be sensitive to all parameters with the exception of $\Delta \mathrm{H}_{\mathrm{ads}, \mathrm{TBA}}$ and $\Delta \mathrm{S}_{\mathrm{ads}, \mathrm{TBA}}$ (Figure 8). The lack of sensitivity is rationalized by considering the coverage of TBA under reaction conditions, as TBA saturated the surface regardless of the reaction condition. Minor changes in the highly favorable energetics of TBA adsorption do not change the surface coverage of TBA, and as a result, no change in the STY of Hofmann elimination. $\Delta \mathrm{H}_{\mathrm{ads}, \mathrm{TBA}}$ and $\Delta \mathrm{S}_{\mathrm{ads}, \mathrm{TBA}}$ were therefore excluded from any further parameter estimation and fixed at their initial estimates.

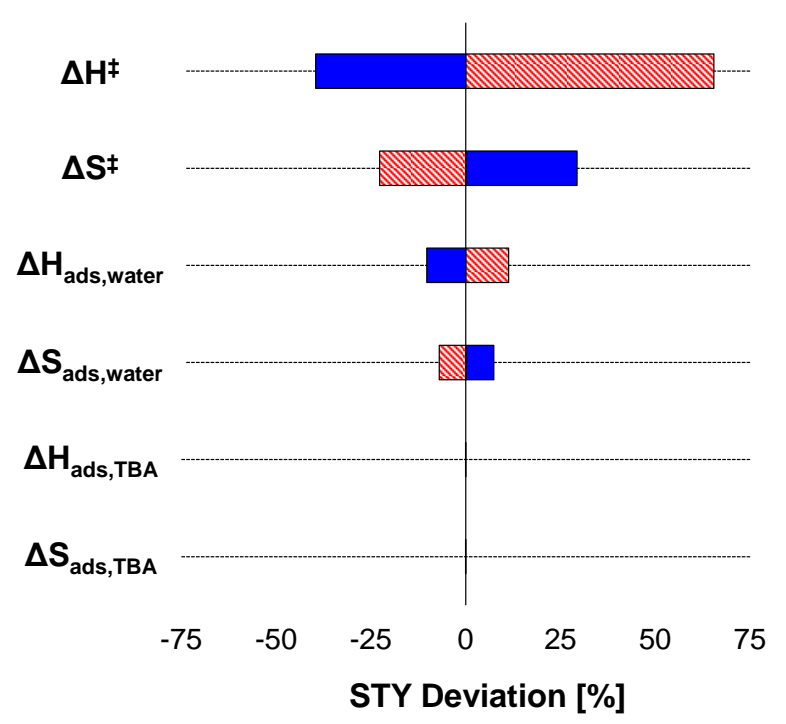

Figure 8. Sensitivity analysis for kinetic and thermodynamic parameters involved in Eq. 12, calculated at $\mathrm{T}=473 \mathrm{~K}, \mathrm{P}_{\mathrm{TBA}}=1.4 \mathrm{kPa}$ and $\mathrm{P}_{\text {water }}=$ $24 \mathrm{kPa}$. STY deviations correspond to $1 \%$ positive (solid fill) and negative (patterned fill) perturbations in each parameter.

\subsubsection{Regression to Experimental Macroscopic Observables. As shows in Table 3, an initial regression of the four sensitive parameters lead to a reasonable statistical fit $\left(\mathrm{R}^{2}=0.97\right)$, where the proposed kinetic model can reconcile experimentally measured rates across all reaction conditions (supporting information, Initial Regression.m). However, regressed values for the enthalpy and entropy of water adsorption were accompanied}


by large confidence intervals $\left(\Delta \mathrm{H}_{\mathrm{ads}, \text { water }}=-53 \pm\right.$ $\left.21 \mathrm{~kJ} \mathrm{~mol}^{-1}, \Delta \mathrm{S}_{\text {ads,water }}=-95 \pm 43 \mathrm{~J} \mathrm{~mol}^{-1} \mathrm{~K}^{-1}\right)$, such that they were not statistically distinguishable from their initial estimates. The two parameters are likely coupled, which leads to significant statistical error in simultaneously estimating both values. The enthalpy of adsorption of water is an independent, experimentally measured value, ${ }^{80-81}$ while the entropy of adsorption is an estimate based on a correlation. ${ }^{89}$ We therefore fix the enthalpy of adsorption of water at the value of its initial estimate, decoupling the regression of water's adsorption energetics (supporting information, Optimized_Model.m).

Regression results of the reduced parameter set are illustrated in the last column of Table 3; by fitting three parameters $\left(\Delta \mathrm{H}^{\dagger}, \Delta \mathrm{S}^{\ddagger}\right.$, and $\Delta \mathrm{S}_{\text {ads,water }}$, kinetic trends were quantitatively captured over three orders of magnitude of STY (Figure 9A). The ability of a single rate expression and parameter set to capture measured STYs regardless of $\mathrm{Si} / \mathrm{Al}$ further underscores the experimental observation: water's inhibitory effect on Hofmann elimination is insensitive to the zeolite composition. Consistent with earlier discussion in section 3.3, the optimized enthalpy of activation $\left(168 \pm 3 \mathrm{~kJ} \mathrm{~mol}^{-1}\right)$ is in agreement with the measured apparent activation energy in the absence of water $\left(\mathrm{E}_{\mathrm{a}}=\Delta \mathrm{H}^{\ddagger}+\mathrm{RT}\right)$; measurable macroscopic rates of reaction are equal to microscopic rates of the surface Hofmann elimination. Similarly, the preexponential factor derived from the regressed activation entropy $\left(50 \pm 7 \mathrm{~J} \mathrm{~mol}^{-1} \mathrm{~K}^{-1}\right)$ is on the order of $10^{15}-10^{16} \mathrm{~s}^{-1}$, which is also in agreement with the apparent value. The relatively positive entropy of activation is also indicative of a loose transition state where tertbutylammonium is already significantly dissociated.

While the regressed entropy of adsorption for water $\left(-81 \pm 1 \mathrm{~J} \mathrm{~mol}^{-1} \mathrm{~K}^{-1}\right)$ is marginally different from the initial estimate, its value nevertheless suggests a relatively weakly adsorbed state, consistent with the physically cooperative adsorption state proposed. The physical nature of this phenomenon can be quantitatively understood by considering the relationship between the macroscopically observable apparent activation energy and microscopic surface energetics,

$$
\begin{array}{r}
\mathrm{E}_{\mathrm{a}, \mathrm{app}}=\Delta \mathrm{H}^{\ddagger}+\left(1-\theta_{\mathrm{TBA}}-\theta_{\mathrm{W}-\mathrm{TBA}}\right) \Delta \mathrm{H}_{\mathrm{ads}, \mathrm{TBA}}- \\
\Delta \mathrm{H}_{\mathrm{ads}, \text { water }} \theta_{\mathrm{W}-\mathrm{TBA}}+\mathrm{RT}(14)
\end{array}
$$

where $\theta_{\text {TBA }}$ and $\theta_{\mathrm{W}-\mathrm{TBA}}$ are the fractional coverages of TBA and the cooperatively adsorbed water-TBA complex, respectively. While the TBA adsorption enthalpy appears in Eq. 14, it does not significantly contribute to the apparent barrier; the coverage of TBA and its cooperatively adsorbed water complex is almost always complete $\left(\theta_{\mathrm{TBA}}+\theta_{\mathrm{W}-\mathrm{TBA}} \sim 1\right)$. Under reaction conditions in this work, the apparent activation energy is sensitive only to the partial pressure of water in the vapor phase, and not TBA (Figure 9B). At low water content, the apparent activation energy, corrected for RT, is equal to the enthalpy of activation of the rate determining E1 surface elimination (168 $\left.\mathrm{kJ} \mathrm{mol}^{-1}\right)$. At higher partial pressures, the apparent activation energy approaches the sum of the enthalpy of activation and water adsorption enthalpy (214 $\mathrm{kJ} \mathrm{mol}^{-1}$ ). This behavior is reflected in the coverage of the water complex on the surface, which approaches complete coverage as the apparent activation energy is maximized (Figure 9C). Understanding the stability of the cooperative water-TBA adsorbate explains the impact of water on the Hofmann elimination catalytic cycle over aluminosilicates. 
Table 3. Initial estimates and fitted results of kinetic and thermodynamic parameters from non-linear regression

\begin{tabular}{|c|c|c|c|c|}
\hline Parameter & Units & Initial Estimate & Initial Regression & Optimized Regression \\
\hline$\Delta \mathrm{H}_{\text {ads,TBA }}$ & $\mathrm{kJ} \mathrm{mol}^{-1}$ & $-220^{a}$ & n.s. & - \\
\hline$\Delta S_{\text {ads,TBA }}$ & $\mathrm{J} \mathrm{mol}^{-1} \mathrm{~K}^{-1}$ & $-270^{\mathrm{b}}$ & n.s. & - \\
\hline$\Delta \mathrm{H}_{\text {ads,water }}$ & $\mathrm{kJ} \mathrm{mol}^{-1}$ & $-46^{\mathrm{c}}$ & $-47 \pm 15$ & - \\
\hline$\Delta \mathrm{S}_{\text {ads,water }}$ & $\mathrm{J} \mathrm{mol}^{-1} \mathrm{~K}^{-1}$ & $-65^{\mathrm{d}}$ & $-84 \pm 32$ & $-81 \pm 1$ \\
\hline$\Delta \mathrm{H}^{\ddagger}$ & $\mathrm{kJ} \mathrm{mol}^{-1}$ & $208^{\mathrm{e}}$ & $168 \pm 5$ & $168 \pm 3$ \\
\hline$\Delta S^{*}$ & $\mathrm{~J} \mathrm{~mol}^{-1} \mathrm{~K}^{-1}$ & $197^{\mathrm{e}}$ & $49 \pm 10$ & $50 \pm 7$ \\
\hline SSE & $\mathrm{mol} \mathrm{iC}_{4}^{2}\left(\mathrm{~mol} \mathrm{H}^{+} \mathrm{s}\right)^{-2}$ & $9.4 \times 10^{4}$ & $1.5 \times 10^{-4}$ & $1.5 \times 10^{-4}$ \\
\hline $\mathrm{R}^{2}$ & - & -2.8 & 0.98 & 0.98 \\
\hline
\end{tabular}
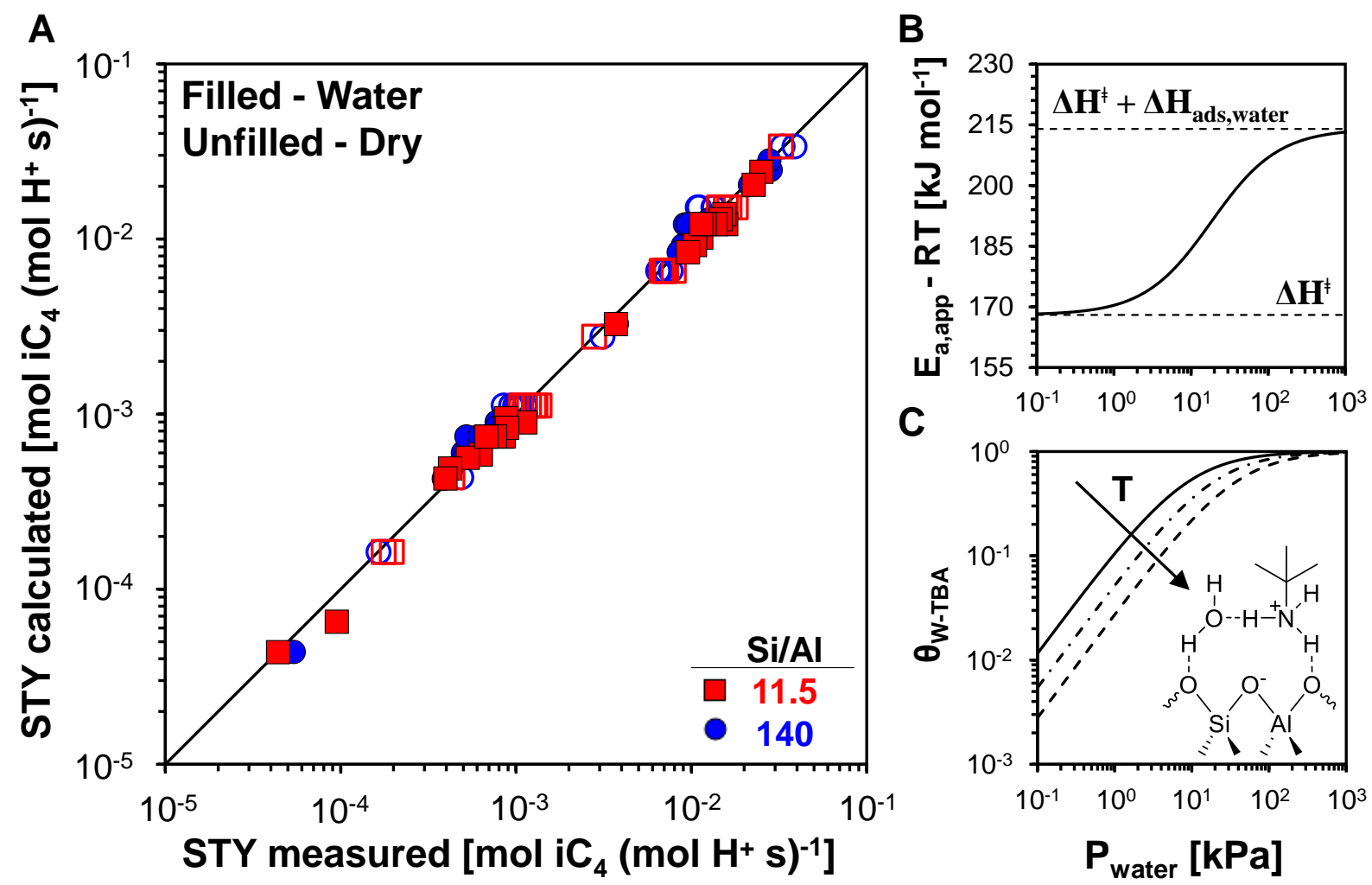

Figure 9. Regression of Cooperative Adsorption Kinetic Model A. Parity plot for the optimal parameter set, illustrating the level of agreement between the predicted and the experimentally measured values of STY of TBA Hofmann elimination. STYs are measured and predicted in the range of T $=453-513 \mathrm{~K}, \mathrm{P}_{\mathrm{TBA}}$ $=0.07-6.7 \mathrm{kPa}, \mathrm{P}_{\text {water }}=0-24 \mathrm{kPa}$. The full data set is provided in the supporting information (Table S8) B. Estimation of apparent activation energy $\left(\mathrm{E}_{\mathrm{a}, \mathrm{app}}\right)$ minus RT as a function of water partial pressure at 483 K C. Predicted fractional coverage of cooperatively adsorbed water-TBA complex $\left(\theta_{\mathrm{W}-\mathrm{TBA}}\right)$ as a function of water partial pressure at $453(-), 483(-.-)$, and $503(---) \mathrm{K}$. 
4. Conclusion. The Hofmann elimination of tert-butylamine is found to proceed selectively over the Brønsted acidic bridging hydroxyls of H-ZSM-5, where a fixed STY is experienced regardless of the $\mathrm{Si} / \mathrm{Al}$ ratio. A comparison of the rate of tert-butyl, sec-butyl and n-butylamine reveals an E1 like carbocation mediated mechanism, where the surface elimination acts as the rate determining step. Given the highly exothermic adsorption of TBA on Brønsted acid sites $\left(-\Delta \mathrm{H}_{\mathrm{ads}}>200 \mathrm{~kJ}\right.$ $\mathrm{mol}^{-1}$ ) relative to all other species, a TBA covered surface is experienced under all the reaction conditions measured in this work. An apparent activation energy to TBA Hofmann elimination of $173 \mathrm{~kJ} \mathrm{~mol}^{-1}$ was measured, which is equivalent to the intrinsic activation energy of the rate determining surface elimination. The introduction of a water cofeed in the vapor phase is found to significantly inhibit the rate of Hofmann elimination, albeit reversibly, where the rate of Hofmann elimination is restored once water is removed. Water is definitively shown not to compete with tert-butylamine adsorbed on Brønsted acid sites; a zeroth order reaction in TBA is maintained in the presence of water and FT-IR measurements reveal no change in TBA coverage. Despite this lack of competition, exactly one water molecule per Brønsted acid site is found to be responsible for the inhibitory effect. The observed loss in activity is physically explained based on a cooperative adsorption mechanism, whereby one water molecule adsorbs on a framework oxygen that neighbors an adsorbed tert-butylammonium, where the interaction between the two species inhibits the Hofmann elimination. The cooperative adsorption is found to be plausible based on quantitative kinetic modeling, based on a set of elementary steps for Hofmann elimination and the cooperative adsorption step. Ultimately, regression of a minimal number of parameters, regardless of $\mathrm{Si} / \mathrm{Al}$, quantitatively captures measured rates of Hofmann elimination over a wide range of reaction conditions. The regressed entropy of adsorption for water $\left(\Delta \mathrm{S}_{\mathrm{ads}}=-81 \pm 1 \mathrm{~J} \mathrm{~mol}^{-1} \mathrm{~K}^{-}\right.$ ${ }^{1}$ ) is consistent with that of a physisorbed molecule, as might be expected from its adsorption on a framework oxygen site in the context of the cooperative adsorption mechanism.

Acknowledgements. We acknowledge support from the Catalysis Center for Energy Innovation, an Energy Frontier Research Center funded by the U.S. Department of Energy, Office of Science, Office of Basic Energy Sciences under Award number DESC0001004. The authors would like to acknowledge Friederike Jentoft, Stavros Caratzoulas and ChoongsZe Lee for helpful discussions.

Supporting Information. Details of the experimental setup, thermodynamic calculations, coverage and rate expression derivations, apparent activation energy profiles and kinetic data sets are available in the supporting information. MATLAB scripts are available as separate files.

Keywords. Hofmann Elimination, Zeolite, Solvent Effect, Water Adsorption, Cooperative Adsorption

\section{References}

1. Mintova, S.; Jaber, M.; Valtchev, V., Nanosized microporous crystals: emerging applications. Chemical Society Reviews 2015, 44 (20), 7207-7233.

2. Gläser, R.; Weitkamp, J. In Basic Principles in Applied Catalysis, Baerns, M., Ed. Springer, Berlin, Heidelberg: Springer Series in Chemical Physics, vol 75, 2004.

3. Bacakova, L.; Vandrovcova, M.; Kopova, I.; Jirka, I., Applications of zeolites in biotechnology and medicine - a review. Biomaterials Science 2018, 6 (5), 974-989.

4. Shi, J.; Wang, Y.; Yang, W.; Tang, Y.; Xie, Z., Recent advances of pore system construction in zeolite-catalyzed chemical industry processes. 


\section{ChemRxiv}

Chemical Society Reviews 2015, 44 (24), 88778903.

5. Chester, A. W.; Derouane, E. G., Zeolite Characterization and Catalysis. Springer, Dordrecht: 2009.

6. Wu, C.-Y.; Wu, H.-S., Ethylene Formation from Ethanol Dehydration Using ZSM-5 Catalyst. ACS Omega 2017, 2 (8), 4287-4296.

7. Zhi, Y.; Shi, H.; Mu, L.; Liu, Y.; Mei, D.; Camaioni, D. M.; Lercher, J. A., Dehydration Pathways of 1-Propanol on HZSM-5 in the Presence and Absence of Water. Journal of the American Chemical Society 2015, 137 (50), 1578115794.

8. Gilbert, C. J.; Espindola, J. S.; Conner Jr, W. C.; Trierweiler, J. O.; Huber, G. W., The Effect of Water on Furan Conversion over ZSM-5. ChemCatChem 2014, 6 (9), 2497-2500.

9. Gumidyala, A.; Wang, B.; Crossley, S., Direct carbon-carbon coupling of furanics with acetic acid over Brønsted zeolites. 2016, 2 (9), e1601072.

10. Cho, H. J.; Ren, L.; Vattipalli, V.; Yeh, Y.H.; Gould, N.; Xu, B.; Gorte, R. J.; Lobo, R.; Dauenhauer, P. J.; Tsapatsis, M.; Fan, W., Renewable p-Xylene from 2,5-Dimethylfuran and Ethylene Using Phosphorus-Containing Zeolite Catalysts. ChemCatChem 2017, 9 (3), 398-402.

11. Cho, H. J.; Kim, D.; Li, J.; Su, D.; Xu, B., Zeolite-Encapsulated Pt Nanoparticles for Tandem Catalysis. Journal of the American Chemical Society 2018, 140 (41), 13514-13520.

12. Iliopoulou, E. F.; Triantafyllidis, K. S.; Lappas, A. A., Overview of catalytic upgrading of biomass pyrolysis vapors toward the production of fuels and high-value chemicals. WIREs Energy and Environment 2019, 8 (1), e322.

13. Resasco, D. E.; Wang, B.; Crossley, S., Zeolite-catalysed $\mathrm{C}-\mathrm{C}$ bond forming reactions for biomass conversion to fuels and chemicals. Catalysis Science \& Technology 2016, 6 (8), 25432559.

14. Ji, Y.; Lawal, A.; Nyholm, A.; Gorte, R. J.; Abdelrahman, O. A., Dehydra-decyclization of tetrahydrofurans to diene monomers over metal oxides. Catalysis Science \& Technology 2020, 10 (17), 5903-5912.

15. Li, S.; Abdelrahman, O. A.; Kumar, G.; Tsapatsis, M.; Vlachos, D. G.; Caratzoulas, S.; Dauenhauer, P. J., Dehydra-Decyclization of Tetrahydrofuran on H-ZSM5: Mechanisms,
Pathways, and Transition State Entropy. ACS Catalysis 2019, 9 (11), 10279-10293.

16. Bond, J. Q.; Jungong, C. S.; Chatzidimitriou, A., Microkinetic analysis of ring opening and decarboxylation of $\gamma$-valerolactone over silica alumina. Journal of Catalysis 2016, 344, 640-656.

17. Gardner, D. W.; Huo, J.; Hoff, T. C.; Johnson, R. L.; Shanks, B. H.; Tessonnier, J.-P., Insights into the Hydrothermal Stability of ZSM-5 under Relevant Biomass Conversion Reaction Conditions. ACS Catalysis 2015, 5 (7), 4418-4422.

18. Chen, K.; Damron, J.; Pearson, C.; Resasco, D.; Zhang, L.; White, J. L., Zeolite Catalysis: Water Can Dramatically Increase or Suppress Alkane C-H Bond Activation. ACS Catalysis 2014, 4 (9), 3039-3044.

19. Li, G.; Wang, B.; Chen, B.; Resasco, D. E., Role of water in cyclopentanone self-condensation reaction catalyzed by MCM-41 functionalized with sulfonic acid groups. Journal of Catalysis 2019, 377, 245-254.

20. Hawkins, A. P.; Zachariou, A.; Parker, S. F.; Collier, P.; Barrow, N.; Silverwood, I. P.; Howe, R. F.; Lennon, D., Effect of steam de-alumination on the interactions of propene with H-ZSM-5 zeolites. RSC Advances 2020, 10 (39), 2313623147.

21. Xu, M.; Lunsford, J. H.; Goodman, D. W.; Bhattacharyya, A., Synthesis of dimethyl ether (DME) from methanol over solid-acid catalysts. Applied Catalysis A: General 1997, 149 (2), 289301.

22. Chen, K.; Kelsey, J.; White, J. L.; Zhang, L.; Resasco, D., Water Interactions in Zeolite Catalysts and Their Hydrophobically Modified Analogues. ACS Catalysis 2015, 5 (12), 7480-7487. 23. Bates, J. S.; Bukowski, B. C.; Greeley, J.; Gounder, R., Structure and solvation of confined water and water-ethanol clusters within microporous Brønsted acids and their effects on ethanol dehydration catalysis. Chemical Science 2020, 11 (27), 7102-7122.

24. Bregante, D. T.; Flaherty, D. W., Impact of Specific Interactions Among Reactive Surface Intermediates and Confined Water on Epoxidation Catalysis and Adsorption in Lewis Acid Zeolites. ACS Catalysis 2019, 9 (12), 10951-10962.

25. Mei, D.; Lercher, J. A., Effects of Local Water Concentrations on Cyclohexanol Dehydration in H-BEA Zeolites. The Journal of 
Physical Chemistry C 2019, 123 (41), 2525525266.

26. Sushkevich, V. L.; van Bokhoven, J. A., Kinetic study and effect of water on methane oxidation to methanol over copper-exchanged mordenite. Catalysis Science \& Technology 2020, 10 (2), 382-390.

27. Sievers, C.; Noda, Y.; Qi, L.; Albuquerque, E. M.; Rioux, R. M.; Scott, S. L., Phenomena Affecting Catalytic Reactions at Solid-Liquid Interfaces. ACS Catalysis 2016, 6 (12), 8286-8307.

28. Ravenelle, R. M.; Schüßler, F.; D'Amico, A.; Danilina, N.; van Bokhoven, J. A.; Lercher, J. A.; Jones, C. W.; Sievers, C., Stability of Zeolites in Hot Liquid Water. The Journal of Physical Chemistry C 2010, 114 (46), 19582-19595.

29. Gounder, R., Hydrophobic microporous and mesoporous oxides as Brønsted and Lewis acid catalysts for biomass conversion in liquid water. Catalysis Science \& Technology 2014, 4 (9), 2877 2886.

30. Bates, J. S.; Gounder, R., Influence of confining environment polarity on ethanol dehydration catalysis by Lewis acid zeolites. Journal of Catalysis 2018, 365, 213-226.

31. Chen, N. Y., Hydrophobic properties of zeolites. The Journal of Physical Chemistry 1976, 80 (1), 60-64.

32. Bregante, D. T.; Johnson, A. M.; Patel, A. Y.; Ayla, E. Z.; Cordon, M. J.; Bukowski, B. C.; Greeley, J.; Gounder, R.; Flaherty, D. W., Cooperative Effects between Hydrophilic Pores and Solvents: Catalytic Consequences of Hydrogen Bonding on Alkene Epoxidation in Zeolites. Journal of the American Chemical Society 2019, 141 (18), 7302-7319.

33. Phillips, C. B.; Datta, R., Production of Ethylene from Hydrous Ethanol on H-ZSM-5 under Mild Conditions. Industrial \& Engineering Chemistry Research 1997, 36 (11), 4466-4475.

34. Jun, K.; Lee, H.-S.; Roh, H.-S.; Park, S.-E., Highly Water-Enhanced H-ZSM-5 Catalysts for Dehydration of Methanol to Dimethyl Ether. Bulletin of the Korean Chemical Society 2003, 24.

35. Pérez-Uriarte, P.; Ateka, A.; Gamero, M.; Aguayo, A. T.; Bilbao, J., Effect of the Operating Conditions in the Transformation of DME to olefins over a HZSM-5 Zeolite Catalyst. Industrial \& Engineering Chemistry Research 2016, 55 (23), 6569-6578.
36. Gould, N. S.; Xu, B., TemperatureProgrammed Desorption of Pyridine on Zeolites in the Presence of Liquid Solvents. ACS Catalysis 2018, 8 (9), 8699-8708.

37. Zygmunt, S. A.; Curtiss, L. A.; Iton, L. E., Protonation of an H2O Dimer by a Zeolitic Brønsted Acid Site. The Journal of Physical Chemistry B 2001, 105 (15), 3034-3038.

38. Zecchina, A.; Geobaldo, F.; Spoto, G.; Bordiga, S.; Ricchiardi, G.; Buzzoni, R.; Petrini, G., FTIR Investigation of the Formation of Neutral and Ionic Hydrogen-Bonded Complexes by Interaction of H-ZSM-5 and H-Mordenite with $\mathrm{CH} 3 \mathrm{CN}$ and H2O: Comparison with the H-NAFION Superacidic System. The Journal of Physical Chemistry 1996, 100 (41), 16584-16599.

39. Jungsuttiwong, S.; Limtrakul, J.; Truong, T. N., Theoretical Study of Modes of Adsorption of Water Dimer on H-ZSM-5 and H-Faujasite Zeolites. The Journal of Physical Chemistry B 2005, 109 (27), 13342-13351.

40. Jobic, H.; Tuel, A.; Krossner, M.; Sauer, J., Water in Interaction with Acid Sites in H-ZSM-5 Zeolite Does Not Form Hydroxonium Ions. A Comparison between Neutron Scattering Results and ab Initio Calculations. The Journal of Physical Chemistry 1996, 100 (50), 19545-19550.

41. Zhao, Z.; Bababrik, R.; Xue, W.; Li, Y.; Briggs, N. M.; Nguyen, D.-T.; Nguyen, U.; Crossley, S. P.; Wang, S.; Wang, B.; Resasco, D. E., Solvent-mediated charge separation drives alternative hydrogenation path of furanics in liquid water. Nature Catalysis 2019, 2 (5), 431-436.

42. Vjunov, A.; Derewinski, M. A.; Fulton, J. L.; Camaioni, D. M.; Lercher, J. A., Impact of Zeolite Aging in Hot Liquid Water on Activity for Acid-Catalyzed Dehydration of Alcohols. Journal of the American Chemical Society 2015, 137 (32), 10374-10382.

43. Buniazet, Z.; Couble, J.; Bianchi, D.; Rivallan, M.; Cabiac, A.; Maury, S.; Loridant, S., Unravelling water effects on solid acid catalysts: Case study of $\mathrm{TiO} 2 / \mathrm{SiO} 2$ as a catalyst for the dehydration of isobutanol. Journal of Catalysis 2017, 348, 125-134.

44. Dai, Q.-L.; Yan, B.; Liang, Y.; Xu, B.-Q., Water effects on the acidic property of typical solid acid catalysts by 3,3-dimethylbut-1-ene isomerization and 2-propanol dehydration reactions. Catalysis Today 2017, 295, 110-118. 
45. Kunz, L. Y.; Bu, L.; Knott, B. C.; Liu, C.; Nimlos, M. R.; Assary, R. S.; Curtiss, L. A.; Robichaud, D. J.; Kim, S., Theoretical Determination of Size Effects in Zeolite-Catalyzed Alcohol Dehydration. Catalysts 2019, 9 (9).

46. Tarach, K. A.; Tekla, J.; Makowski, W.; Filek, U.; Mlekodaj, K.; Girman, V.; Choi, M.; Góra-Marek, K., Catalytic dehydration of ethanol over hierarchical ZSM-5 zeolites: studies of their acidity and porosity properties. Catalysis Science \& Technology 2016, 6 (10), 3568-3584.

47. Aronson, M. T.; Gorte, R. J.; Farneth, W. E., The influence of oxonium ion and carbenium ion stabilities on the Alcohol/H-ZSM-5 interaction. Journal of Catalysis 1986, 98 (2), 434-443.

48. Alexopoulos, K.; John, M.; Van der Borght, K.; Galvita, V.; Reyniers, M.-F.; Marin, G. B., DFT-based microkinetic modeling of ethanol dehydration in H-ZSM-5. Journal of Catalysis 2016, 339, 173-185.

49. Batchu, R.; Galvita, V. V.; Alexopoulos, K.; Glazneva, T. S.; Poelman, H.; Reyniers, M.-F.; Marin, G. B., Ethanol dehydration pathways in $\mathrm{H}-$ ZSM-5: Insights from temporal analysis of products. Catalysis Today 2020, 355, 822-831.

50. Jones, A. J.; Iglesia, E., Kinetic, Spectroscopic, and Theoretical Assessment of Associative and Dissociative Methanol Dehydration Routes in Zeolites. Angewandte Chemie International Edition 2014, 53 (45), 1217712181.

51. Carr, R. T.; Neurock, M.; Iglesia, E., Catalytic consequences of acid strength in the conversion of methanol to dimethyl ether. Journal of Catalysis 2011, 278 (1), 78-93.

52. Ortega, C.; Rezaei, M.; Hessel, V.; Kolb, G., Methanol to dimethyl ether conversion over a ZSM-5 catalyst: Intrinsic kinetic study on an external recycle reactor. Chemical Engineering Journal 2018, 347, 741-753.

53. Di Iorio, J. R.; Hoffman, A. J.; Nimlos, C. T.; Nystrom, S.; Hibbitts, D.; Gounder, R., Mechanistic origins of the high-pressure inhibition of methanol dehydration rates in small-pore acidic zeolites. Journal of Catalysis 2019, 380, 161-177.

54. Parrillo, D. J.; Adamo, A. T.; Kokotailo, G. T.; Gorte, R. J., Amine adsorption in H-ZSM-5. Applied Catalysis 1990, 67 (1), 107-118.

55. Malysheva, L. V.; Paukshtis, E. A.; Kotsarenko, N. S., Interaction of butylamines with protonic centers of $\mathrm{HNaY}$ zeolite. Reaction Kinetics and Catalysis Letters 1984, 24 (1), 97-101.

56. Aguayo, A. T.; Gayubo, A. G.; Ereña, J.; Olazar, M.; Arandes, J. M.; Bilbao, J., Isotherms of chemical adsorption of bases on solid catalysts for acidity measurement. Journal of Chemical Technology \& Biotechnology 1994, 60 (2), 141146.

57. Ho, C. R.; Bettinson, L. A.; Choi, J.; HeadGordon, M.; Bell, A. T., Zeolite-Catalyzed Isobutene Amination: Mechanism and Kinetics. ACS Catalysis 2019, 9 (8), 7012-7022.

58. Abdelrahman, O. A.; Vinter, K. P.; Ren, L.; Xu, D.; Gorte, R. J.; Tsapatsis, M.; Dauenhauer, P. J., Simple quantification of zeolite acid site density by reactive gas chromatography. Catalysis Science \& Technology 2017, 7 (17), 3831-3841.

59. Parrillo, D. J.; Gorte, R. J., Characterization of acidity in H-ZSM-5, H-ZSM-12, H-Mordenite, and $\mathrm{H}-\mathrm{Y}$ using microcalorimetry. The Journal of Physical Chemistry 1993, 97 (34), 8786-8792.

60. Yu, J.; Zhu, S.; Dauenhauer, P. J.; Cho, H. J.; Fan, W.; Gorte, R. J., Adsorption and reaction properties of SnBEA, ZrBEA and H-BEA for the formation of $\mathrm{p}$-xylene from DMF and ethylene. Catalysis Science \& Technology 2016, 6 (14), 5729-5736.

61. Biaglow, A. I.; Parrillo, D. J.; Gorte, R. J., Characterization of $\mathrm{H}, \mathrm{Na}-\mathrm{Y}$ Using Amine Desorption. Journal of Catalysis 1993, 144 (1), 193-201.

62. Kresnawahjuesa, O.; Kühl, G. H.; Gorte, R. J.; Quierini, C. A., An Examination of Brønsted Acid Sites in H-[Fe]ZSM-5 for Olefin Oligomerization and Adsorption. Journal of Catalysis 2002, 210 (1), 106-115.

63. Bordiga, S.; Lamberti, C.; Bonino, F.; Travert, A.; Thibault-Starzyk, F., Probing zeolites by vibrational spectroscopies. Chemical Society Reviews 2015, 44 (20), 7262-7341.

64. Widayat, W.; Annisa, A. N., Synthesis and Characterization of ZSM-5 Catalyst at Different Temperatures. IOP Conference Series: Materials Science and Engineering 2017, 214, 012032.

65. Koros, R. M.; Nowak, E. J., A diagnostic test of the kinetic regime in a packed bed reactor. Chemical Engineering Science 1967, 22 (3), 470.

66. Di Iorio, J. R.; Gounder, R., Controlling the Isolation and Pairing of Aluminum in Chabazite Zeolites Using Mixtures of Organic and Inorganic 
Structure-Directing Agents. Chemistry of Materials 2016, 28 (7), 2236-2247.

67. Parrillo, D. J.; Gorte, R. J.; Farneth, W. E., A calorimetric study of simple bases in H-ZSM-5: a comparison with gas-phase and solution-phase acidities. Journal of the American Chemical Society 1993, 115 (26), 12441-12445.

68. Janda, A.; Bell, A. T., Effects of Si/Al Ratio on the Distribution of Framework $\mathrm{Al}$ and on the Rates of Alkane Monomolecular Cracking and Dehydrogenation in H-MFI. Journal of the American Chemical Society 2013, 135 (51), 1919319207.

69. Malysheva, L. V.; Paukshtis, E. A.; Kotsarenko, N. S., Deamination of butylamines on the surface of acidic oxide catalysts. Reaction Kinetics and Catalysis Letters 1984, 24 (1), 91-95. 70. Malysheva, L. V.; Paukshtis, E. A.; Kotsarenko, N. S., Mechanism of deamination of butylamines on protonic centers of $\mathrm{HNaY}$ zeolite. Journal of Catalysis 1987, 104 (1), 31-36.

71. Demmin, R. A.; Gorte, R. J., Design parameters for temperature-programmed desorption from a packed bed. Journal of Catalysis 1984, 90 (1), 32-39.

72. Gorte, R. J., Design parameters for temperature programmed desorption from porous catalysts. Journal of Catalysis 1982, 75 (1), 164174.

73. Redhead, P. A., Thermal desorption of gases. Vacuum 1962, 12 (4), 203-211.

74. Beránek, L.; Kraus, M. In Comprehensive Chemical Kinetics, Bamford, C. H., Tipper, C. F. H., Eds. Elsevier: 1978; Vol. 20, pp 263-398.

75. Jian-Hua, Z.; Qin-Hua, X., Temperature Programmed Desorption and Thermal Decomposition of n-Butylamine on Zeolite HZSM5. Chinese Science Bulletin 1989, 34 (1001-6538), 384.

76. Almutairi, S. M. T.; Mezari, B.; Pidko, E. A.; Magusin, P. C. M. M.; Hensen, E. J. M., Influence of steaming on the acidity and the methanol conversion reaction of HZSM-5 zeolite. Journal of Catalysis 2013, 307, 194-203.

77. Xue, N.; Vjunov, A.; Schallmoser, S.; Fulton, J. L.; Sanchez-Sanchez, M.; Hu, J. Z.; Mei, D.; Lercher, J. A., Hydrolysis of zeolite framework aluminum and its impact on acid catalyzed alkane reactions. Journal of Catalysis 2018, 365, 359-366. 78. Iwamoto, M.; Mori, H.; Tajima, M.; Kagawa, S., Catalytic Hydration of Butenes over
Proton-Exchanged Zeolites. NIPPON KAGAKU KAISHI 1989, 1989 (3), 586-587.

79. Kikuchi, E.; Matsuda, T.; Shimomura, K.; Kawahara, K.; Morita, Y. In Studies in Surface Science and Catalysis, Murakami, Y., Iijima, A., Ward, J. W., Eds. Elsevier: 1986; Vol. 28, pp 771778.

80. Zhang, K.; Lively, R. P.; Noel, J. D.; Dose, M. E.; McCool, B. A.; Chance, R. R.; Koros, W. J., Adsorption of Water and Ethanol in MFI-Type Zeolites. Langmuir 2012, 28 (23), 8664-8673.

81. Ison, A.; Gorte, R. J., The adsorption of methanol and water on H-ZSM-5. Journal of Catalysis 1984, 89 (1), 150-158.

82. Lee, C. C.; Gorte, R. J.; Farneth, W. E., Calorimetric Study of Alcohol and Nitrile Adsorption Complexes in H-ZSM-5. The Journal of Physical Chemistry B 1997, 101 (19), 3811-3817.

83. Kletnieks, P. W.; Ehresmann, J. O.; Nicholas, J. B.; Haw, J. F., Adsorbate Clustering and Proton Transfer in Zeolites: NMR Spectroscopy and Theory. ChemPhysChem 2006, 7 (1), 114-116.

84. Bordiga, S.; Regli, L.; Lamberti, C.; Zecchina, A.; Bjørgen, M.; Lillerud, K. P., FTIR Adsorption Studies of $\mathrm{H} 2 \mathrm{O}$ and $\mathrm{CH} 3 \mathrm{OH}$ in the Isostructural H-SSZ-13 and H-SAPO-34: Formation of H-Bonded Adducts and Protonated Clusters. The Journal of Physical Chemistry B 2005, 109 (16), 7724-7732.

85. Jentys, A.; Warecka, G.; Derewinski, M.; Lercher, J. A., Adsorption of water on ZSM 5 zeolites. The Journal of Physical Chemistry 1989, 93 (12), 4837-4843.

86. Joshi, K. L.; Psofogiannakis, G.; van Duin, A. C. T.; Raman, S., Reactive molecular simulations of protonation of water clusters and depletion of acidity in H-ZSM-5 zeolite. Physical Chemistry Chemical Physics 2014, 16 (34), 1843318441.

87. Sazama, P.; Tvarůžková, Z.; Jirglová, H.; Sobalík, Z. In Studies in Surface Science and Catalysis, Gédéon, A., Massiani, P., Babonneau, F., Eds. Elsevier: 2008; Vol. 174, pp 821-824.

88. Gao, X.; Heyden, A.; Abdelrahman, O. A.; Bond, J. Q., Microkinetic analysis of acetone hydrogenation over $\mathrm{Pt} / \mathrm{SiO} 2$. Journal of Catalysis 2019, 374, 183-198.

89. Dauenhauer, P. J.; Abdelrahman, O. A., A Universal Descriptor for the Entropy of Adsorbed 
Molecules in Confined Spaces. ACS Central

Science 2018, 4 (9), 1235-1243. 